\title{
SIMILARIDADES ENTRE SOLOS COESOS E HARDSETTING: CARACTERIZAÇÃO DO COMPORTAMENTO FÍSICO
}

\author{
NEYDE FABÍOLA BALAREZO GIAROLA
}

Tese apresentada à Escola Superior de Agricultura "Luiz de Queiroz", Universidade de São Paulo, para a obtenção do título de Doutor em Agronomia, Área de Concentração: Solos e Nutrição de Plantas.

PIRACICABA

Estado de São Paulo - Brasil

Abril - 2002 


\section{SIMILARIDADES ENTRE SOLOS COESOS E HARDSETTING: CARACTERIZAÇÃO DO COMPORTAMENTO FÍSICO}

\section{NEYDE FABÍOLA BALAREZO GIAROLA}

Engenheiro Agrônomo

Orientador: Prof. Dr. ALVARO PIRES DA SILVA

Tese apresentada à Escola Superior de Agricultura "Luiz de Queiroz", Universidade de São Paulo, para a obtenção do título de Doutor em Agronomia, Área de Concentração: Solos e Nutrição de Plantas.

PIRACICABA

Estado de São Paulo - Brasil

Abril - 2002 


\section{Dados Internacionais de Catalogação na Publicação (CIP) DIVISÃO DE BIBLIOTECA E DOCUMENTAÇÃO - ESALQ/USP}

Giarola, Neyde Fabíola Balarezo

Similaridade entre solos coesose Ha rd setting: c aracterização do

comportamento físico / Neyde Fabíola Balarezo Giarola. - - Piracic aba, 2002.

65 p. : il.

Tese (doutorado) - Escola Superior de Agricultura Luiz de Queiroz, 2002.

Bibliografia.

1. Gênese do solo 2. Físic a do solo 3. Morfologia do solo 4. Resistência dos solos 5. Tipologia do solo I. Título

CDD 631.43

"Permitida a cópia total ou parcial deste documento, desde que citada a fonte - $O$ autor" 


\section{AGRADECIMENTOS}

Ao Professor Alvaro Pires da Silva e à amiga Silvia Imhoff, pelos ensinamentos e amizade.

Aos pesquisadores Luciano da Silva Souza (CNPMF/EMBRAPA) e Mariza Nascimento Duarte (CNPS/EMBRAPA - in memorian), pelo auxílio indispensável no desenvolvimento do trabalho.

À Universidade Estadual do Oeste do Paraná e à ESALQ/USP, pela oportunidade de realizar o curso.

À CAPES, pela concessão da bolsa de estudos.

À Coordenação do Programa de Pós-Graduação em Solos e Nutrição de Plantas da ESALQ/USP. 


\section{SUMÁRIO}

Página

RESUMO …............................................................................ vi

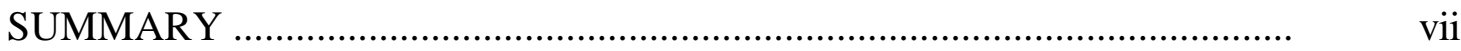

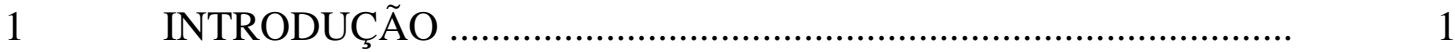

2 REVISÃO DE LITERATURA .................................................. 3

2.1 Conceitos sobre solos coesos e hardsetting: considerações gerais .... 3

2.2 Definição e ocorrência de solos coesos ...............................................

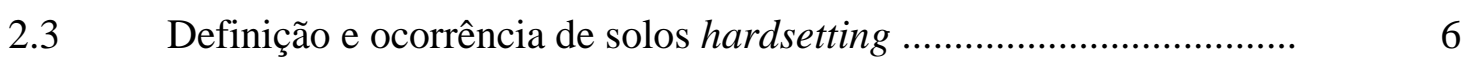

2.4 Mecanismos relacionados à gênese dos solos com caráter coeso ..... 8

2.5 Mecanismos relacionados à gênese dos solos com comportamento hardsetting .......................................................................... 9

2.6 Características dos solos coesos ................................................ 10

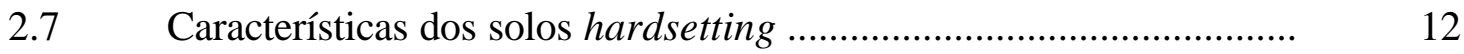

2.8 Problemas relacionados aos solos com elevada resistência, quando

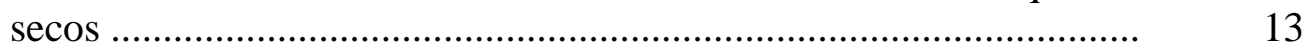

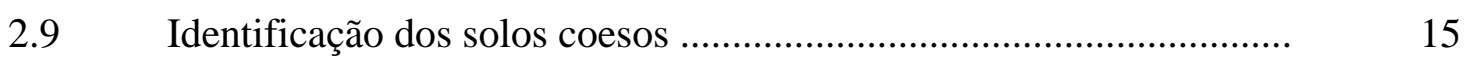

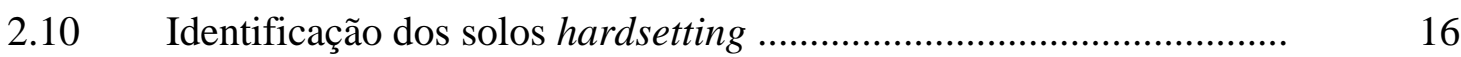

3 SIMILARIDADES ENTRE O CARÁTER COESO DOS SOLOS E O COMPORTAMENTO HARDSETTING: ESTUDO DE CASO 18

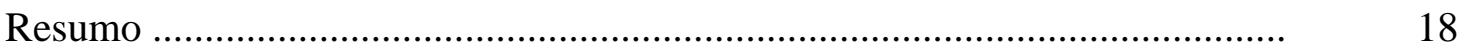

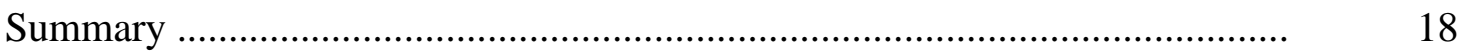

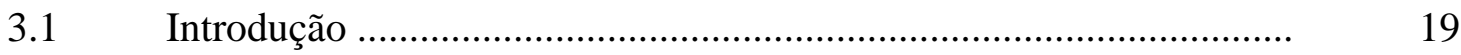

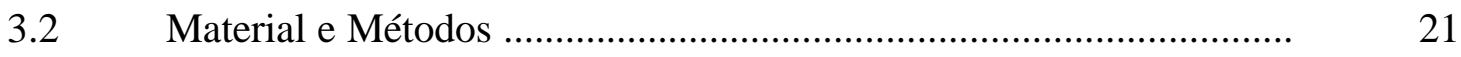

3.2.1 Solo e local de amostragem ................................................... 21 
3.2.2 Critérios adotados para a análise das similaridades ........................... 22

3.2.3 Metodologia de análise .............................................................. 22

3.2.3.1 Morfologia do perfil ................................................................... 22

3.2.3.2 Elaboração das curvas de resistência do solo .................................... 23

3.2.3.3 Análises complementares ........................................................... 23

3.3 Resultados e Discussão ............................................................ 24

Conclusões ............................................................................

4 CONTRIBUIÇÃO DO ADENSAMENTO NATURAL DAS PARTÍCULAS DO SOLO NA OCORRÊNCIA DO CARÁTER HARDSETTING ....................................................................... 36

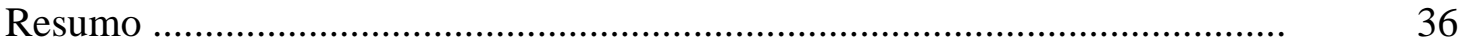

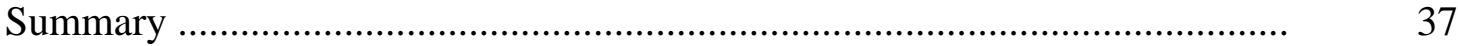

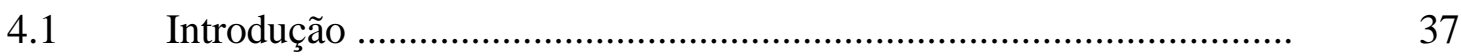

4.2 Material e Métodos ................................................................... 39

4.2.1 Área de estudo e solo selecionado ................................................ 39

4.2.2 Lâminas delgadas e microtorrões ................................................ 41

4.2.3 Torrões do solo ................................................................... 41

4.2.4 Amostras indeformadas ......................................................... 42

4.2.5 Análise estatística ............................................................................

4.3 Resultados e Discussão ............................................................ 43

4.3.1 Feições micromorfológicas ........................................................ 43

4.3.2 Resistência tênsil .........................................................................

4.3.3 Resistência do solo versus estresse efetivo .................................... 48

Conclusões ...................................................................... 52

$5 \quad$ CONCLUSÕES GERAIS ...................................................... 53

REFERÊNCIAS BIBLIOGRÁFICAS ..................................................... 55 


\title{
SIMILARIDADES ENTRE SOLOS COESOS E HARDSETTING: CARACTERIZAÇÃO DO COMPORTAMENTO FÍSICO
}

\author{
Autora: NEYDE FABÍOLA BALAREZO GIAROLA \\ Orientador: Prof. Dr. ALVARO PIRES DA SILVA
}

\section{RESUMO}

Horizontes coesos de solos da região nordeste do Brasil, faixa de domínio dos Tabuleiros Costeiros, são uma séria limitação para a produtividade das culturas devido ao incremento acentuado da resistência do solo à penetração, sob condições de secamento do solo. Solos similares foram reconhecidos na Austrália e identificados como hardsetting. $\mathrm{O}$ objetivo desta pesquisa foi demonstrar que o caráter coeso de um Latossolo Amarelo localizado na Bahia é equivalente ao atributo hardsetting utilizado na descrição do solos australianos. A tese foi dividida em três capítulos. O primeiro capítulo apresenta uma revisão de literatura sobre os conceitos que norteiam os designativos coeso e hardsetting. O segundo capítulo descreve uma pesquisa de campo que demonstra que solos com caráter coeso e hardsetting apresentam o mesmo comportamento, no que diz respeito às feições morfológicas e resistência à penetração. O terceiro capítulo apresenta um estudo de laboratório que demonstrou, por meio da análise de parâmetros físicos e micromorfológicos, que o adensamento natural das partículas foi o principal fator que contribuiu com a ocorrência do caráter coeso do solo.

Palavras-chave: solos dos Tabuleiros Costeiros, horizontes adensados, morfologia do solo, resistência do solo, estresse efetivo. 


\title{
SIMILARITIES BETWEEN COHESIVE AND HARDSETTING SOILS: PHYSICAL BEHAVIOR CHARACTERIZATION
}

\author{
Author: NEYDE FABÍOLA BALAREZO GIAROLA \\ Adviser: Prof. Dr. ALVARO PIRES DA SILVA
}

\section{SUMMARY}

"Cohesive" soil horizons from the northeastern region of Brazil, domain of Low Coastal Tablelands, represents a serious limitation for crop production due to the huge increase in soil resistance to penetration as the soil dries. Similar soils have been reported in Australia and identified as hardsetting. The objective of this research was to demonstrate that a Yellow Cohesive Latosol located in Bahia is equivalent to the hardsetting attribute used in the description of Australian soils. The thesis was divide in three chapters. The first chapter presents a literature review on the "cohesive" and hardsetting concepts. The second chapter describes a field research showing that a "cohesive" and a hardsetting soil have the same behavior regarding their morphological features and resistance to penetration. The third chapter presents a laboratory study where is demonstrated that the natural densification of soil particles has a major contribution on the "cohesive" behavior.

Key words: Low Coastal Tablelands soils, compacted horizons, soil morphology, soil strength, effective stress. 


\section{INTRODUÇÃO}

O caráter "coeso", atribuído a solos do Brasil (EMBRAPA, 1999), é empregado para distinguir horizontes minerais de solos da faixa dos Tabuleiros Costeiros que apresentam consistência dura, muito dura ou até extremamente dura, quando secos, e friável, quando úmidos (Ribeiro, 1991; EMBRAPA, 1995; Jacomine, 1996). Os horizontes coesos são uma séria limitação do meio físico para obtenção de elevadas produtividades das culturas pois, no período seco, apresentam resistência do solo à penetração restritiva ao desenvolvimento das raízes, que as impedem de manifestarem todo seu potencial genético de produção.

Solos com comportamento similar têm sido reconhecidos em diversos países e são denominados hardsetting (Mullins et al., 1987; Mullins et al., 1990). Hardsetting é um atributo de solo que caracteriza horizontes de solos que, quando secos, desenvolvem alta resistência mecânica e estruturação aparente pouco expressa ou ausente (maciça) e, quando úmidos, perdem boa parte dessa resistência, tornando-se friáveis (McDonald et al., 1998; Mullins et al., 1990; Mullins, 1999). São potencialmente limitantes ao cultivo de grãos pois, principalmente, no período seco, dificultam ou mesmo impossibilitam a realização das operações de preparo e o desenvolvimento das plantas.

As características e a dinâmica de formação dos solos com horizontes coesos e hardsetting ainda não são de todo conhecidas. A gênese dos coesos é um assunto polêmico, estando associada a processos como: à perda do plasma argiloso das camadas superficiais do solo para as camadas subjacentes, à presença de sílica secundária, ferro e argila dispersa nos microporos, e ao adensamento por dessecação resultante da alteração da estrutura do solo pela alternância de ciclos de umedecimento e secagem (Ribeiro, 1986; Ponte \& Ribeiro, 1990). A ocorrência do caráter hardsetting tem sido relacionada 
à atuação de agentes químicos cimentantes temporários como sílica amorfa e aluminosilicatos, associados à alternância entre climas úmido e seco (Chartres et al.,1990; Chartres \& Norton, 1994; Franzmeier et al., 1996). A influência de processos físicos também tem sido ressaltada nos hardsetting (Mullins et al., 1992a; Mullins et al, 1992b; Weaich et al., 1992b), principalmente o papel do estresse efetivo, na geração de altos níveis de resistência do solo (Mullins \& Panayiotopolous, 1984; Mullins, 1989; Ley et al., 1993), como também o efeito direto da densidade do solo sobre os valores de resistência do solo, independente do estresse efetivo (Vepraskas, 1984).

A literatura sugere que ocorrem solos hardsetting em áreas do Brasil em que são comuns os solos coesos (Mullins et al., 1987; Mullins et al., 1990). A partir das indicações da literatura, levantoutse a hipótese de que o caráter coeso descrito no Sistema Brasileiro de Classificação de Solos para Latossolos Amarelos da faixa dos Tabuleiros Costeiros é similar ao comportamento hardsetting observado em solos da Austrália, África e outras regiões tropicais, sendo decorrente da atuação de processos físicos.

O objetivo geral desta tese foi determinar se o caráter coeso de um Latossolo Amarelo da região nordeste do Brasil é similar ao atributo hardsetting utilizado na descrição do solos da Austrália, por meio de parâmetros morfológicos e físicos sugeridos em literatura. Para alcançar o objetivo geral, a pesquisa foi subdividida em três partes, cada uma contemplada num capítulo distinto. No primeiro capítulo, apresenta-se uma revisão de literatura sobre os conceitos que norteiam o designativo "coeso", proveniente do sistema taxonômico brasileiro (Jacomine, 1996; Ribeiro, 1998; EMBRAPA, 1999), e o atributo hardsetting, oriundo do sistema australiano de classificação de solos (Northcote et al., 1975). No segundo capítulo, relata-se um estudo de campo sobre as similaridades entre o caráter coeso do Latossolo Amarelo selecionado e os atributos físicos e morfológicos sugeridos, pela literatura, para a identificação do comportamento hardsetting. O terceiro capítulo encerra a pesquisa, em laboratório, com um estudo sobre a contribuição do adensamento natural das partículas na ocorrência de horizontes com comportamento hardsetting, por meio da análise de parâmetros físicos e micromorfológicos. 


\section{REVISÃO DE LITERATURA}

\subsection{Conceitos sobre solos coesos e hardsetting: considerações gerais}

Diferenças marcantes entre os graus de consistência do solo seco e úmido, principalmente em termos de incremento do grau de consistência a seco (resistência), podem ser observadas em alguns horizontes de solos da faixa dos Tabuleiros Costeiros, nas regiões Sudeste e Nordeste do Brasil ( Jacomine, 1996; Ribeiro, 1998; Giarola et al., 2001). Esse tipo de comportamento de solo foi incorporado ao Sistema Brasileiro de Classificação de Solo por meio da criação e utilização do designativo "coeso" (EMBRAPA, 1999).

O termo "coeso" caracteriza materiais de solo que, quando secos, apresentam um incremento acentuado de resistência (a ponto de restringir o preparo do solo e o desenvolvimento das culturas), e se abrandam, no momento em que são umedecidos (Jacomine, 1996; Ribeiro, 1998; EMBRAPA, 1999; Ribeiro, M.R., 2001). Devido à ocorrência de solos com esse comportamento em uma extensa área do território brasileiro (Jacomine, 1996; Rezende, 2000), o atributo coeso foi incluído no sistema taxonômico nacional, aparecendo como característica diagnóstica da classe dos Latossolos Amarelos (EMBRAPA, 1999).

$\mathrm{Na}$ Austrália, diferenças em termos de consistência há muito foram incorporadas ao sistema de classificação de solos, por intermédio do atributo hardsetting (Northcote et al., 1975; Harper \& Gilkes, 1994). Esse atributo caracteriza solos com horizontes compactos, duros, de condição aparentemente apedal formada durante o secamento, mas que se abranda durante o umedecimento (McDonald et al., 1998). Os horizontes hardsetting se endurecem significativamente, quando secos, dificultando ou mesmo 
impossibilitando o preparo para o cultivo, e cessam esse impedimento, no momento em que são umedecidos (Mullins et al., 1990; Mullins, 1999). Existem características comuns entre o comportamento hardsetting e outros tipos de comportamento de solo, como por exemplo os fragipãs. No entanto, os horizontes hardsetting não devem ser confundidos com fragipãs, que também têm altos níveis de coesão, mas apresentam pedogênese diversa, ocorrem a maiores profundidades e têm diferentes implicações em relação ao manejo (Harlan et al., 1977; Smeck \& Ciolkosz, 1989; Chartres \& Fitzgerald, 1990).

A possibilidade de existirem solos com comportamento similar aos hardsetting, no Brasil, já havia sido aventada por Mullins et al. (1990), após percorrerem áreas de ocorrência de solos coesos, na região nordeste do país. O que para os australianos seriam solos hardsetting, no Brasil seriam os coesos. Essa hipótese foi comprovada por Giarola et al. (2001), após encontrarem uma série de similaridades entre os parâmetros utilizados para definir o comportamento hardsetting e aqueles para determinar o caráter coeso em um Latossolo Amarelo do nordeste brasileiro.

Esta revisão de literatura teve como objetivo levantar e contrapor os conceitos até então estabelecidos para o atributo hardsetting, oriundo do sistema australiano de classificação de solos, e para o designativo coeso, utilizado no sistema taxonômico brasileiro.

\subsection{Definição e ocorrência de solos coesos}

O termo coeso tem sido empregado, no Brasil, para distinguir horizontes minerais superficiais e subsuperficiais de solo que apresentam consistência dura, muito dura ou até extremamente dura, quando secos, e friável, quando úmidos (Jacomine, 1996). Ribeiro (1991) definiu os horizontes que apresentavam o caráter coeso da seguinte forma: "são horizontes muito duros e firmes, que não apresentam uma organização estrutural visível (são maciços), motivo pelo qual os grandes torrões se quebram em fragmentos de tamanhos menores e angulosos; apresentam uma macroporosidade geralmente ligada à atividade biológica (biovazios), sendo difícil a 
observação dos poros finos; no seu interior são raras as raízes observadas, mesmo assim, a grande maioria das que conseguiram penetrar nesses horizontes encontram-se mortas; em alguns pontos pode-se observar uma organização estrutural fragmentar, com a presença de estrutura do tipo blocos subangulares, geralmente associados a pequenas concentrações de material orgânico originado da decomposição de raízes ou atividade biológica (crotovinas e ninhos); em muitos casos é possível observar, ainda que com alto grau de dificuldade, e com uso de lupa, a existência de uma microestrutura soldada, como uma colmeia de abelhas".

O atual sistema taxonômico brasileiro (EMBRAPA, 1999) estabelece que os Latossolos Amarelos Coesos são "solos com um ou mais horizontes com espessura mínima de $30 \mathrm{~cm}$, que não satisfaz os critérios para fragipã ou duripã, compreendendo o horizonte $\mathrm{AB}$ e/ou $\mathrm{BA}$, e/ou parte do $\mathrm{Bw}$, os quais, quando secos, são muito resistentes à penetração do martelo pedológico ou trado e que não apresentam uma organização estrutural visível (são maciços) e que se desfaz em agregados com consistência a seco, no mínimo, dura, sendo normalmente muito dura, e às vezes, extremamente dura. A consistência úmida varia de friável a firme; a densidade do solo deste horizonte é mais elevada que os horizontes subjacentes; a saturação por bases é baixa ( $\mathrm{V}<50 \%$ ), e o teor de $\mathrm{Fe}_{2} \mathrm{O}_{3}$ (pelo $\mathrm{H}_{2} \mathrm{SO}_{4}$ ) é menor que $8 \%$ e o $\mathrm{Ki}$ é 1,7 ou maior, isto é, são cauliníticos”.

A ocorrência do caráter coeso, no Brasil, vem sendo relacionada aos antigos Latossolos e Podzólicos Amarelos desenvolvidos dos sedimentos do Grupo Barreiras (Fonseca, 1986; Jacomine, 1996; Rezende, 2000), que ocupam, preferencialmente, os aplainados dos topos dos tabuleiros e estão restritos à zona úmida costeira do litoral oriental das regiões Nordeste e Sudeste, sob climas de estações secas e úmidas bem definidas (Jacomine, 1996; Ribeiro, 1998; Jacomine, 2001). Abrange, aproximadamente, dez milhões de hectares, apenas no Nordeste brasileiro (Rezende, 2000).

O caráter "coeso" é uma característica pedogenética (adensamento) de solos, típica de horizontes subsuperficiais (BA e/ou parte do Bw ou Bt), de textura média, argilosa ou muito argilosa, encontrados normalmente entre 30 e $70 \mathrm{~m}$ de profundidade (Jacomine, 1996; Rezende, 2000; Jacomine, 2001; Ribeiro, M.R., 2001), mas se estende para os horizontes superficiais A e AB em solos cultivados (Ribeiro, M.R., 2001). 
Embora o atual sistema taxonômico brasileiro considere o uso do termo "coeso" apenas para os Latossolos Amarelos desenvolvidos dos sedimentos do Grupo Barreiras, os levantamentos pedológicos já haviam comprovado a existência do mesmo em Argissolos Amarelos latossólicos ou não, Argissolos Acinzentados, Argissolos Amarelos fragipânicos e Plintossolos (Anjos, 1985; Fonseca, 1986; Jacomine, 1996; Nascimento, 2001; Jacomine, 2001; Ribeiro, M.R., 2001). Alguns pedólogos brasileiros acreditam que esse caráter não está restrito apenas aos solos do Grupo Barreiras e que, em outras regiões do Brasil, também se desenvolvem solos com o mesmo comportamento.

\subsection{Definição e ocorrência de solos hardsetting}

O termo hardsetting foi, inicialmente, utilizado por Northcote (1960) em solos de textura binária do Oeste da Austrália e, posteriormente, Northcote (1971) o associou a solos de zonas climáticas que apresentavam variação marcante entre períodos secos e úmidos. Foi somente identificado e mapeado em solos australianos (Northcote et al., 1975 ) mas, posteriormente, reconhecido e utilizado em outras regiões do mundo (Mulins et al., 1990).

O comportamento hardsetting foi definido por McDonald et al. (1984) como: “compacto, duro, condição aparentemente apedal, formada durante o secamento". Uma revisão dessa definição foi apresentada por McDonald et al., (1998): “compacto, duro, condição aparentemente apedal, formada durante o secamento, mas que se abranda durante o umedecimento. Quando seco, o material é duro ... e não é alterado ou não se deforma ao ser pressionado com o dedo indicador". A mais recente definição dada para hardsetting foi apresentada por Mullins (1997): "Um material de solo com comportamento hardsetting é aquele que se torna uma massa quase homogênea ao secar. Apresenta rachaduras ocasionais, normalmente a um espaçamento $\geq 0,1 \mathrm{~m}$. É duro e quebradiço, e a face do perfil de solo que apresenta esse comportamento é indeformável ao ser pressionada com o dedo indicador. Tipicamente, apresenta valores de resistência tênsil $\geq 0,09 \mathrm{MPa}$. Solos que se encrostam não apresentam, necessariamente, 
comportamento hardsetting, pois os horizontes com esse caráter são mais espessos do que uma crosta. Em solos cultivados a espessura do horizonte hardsetting é, freqüentemente, igual ou maior do que a da camada cultivada. Não são permanentemente cimentados e apresentam consistência friável, quando úmidos. Os agregados de um horizonte dessa natureza, que já foi submetido ao cultivo, são parcial ou totalmente desintegrados sob umedecimento. Se o solo foi suficientemente umedecido, se reverterá ao estado hardset, ao secamento. Isso pode acontecer depois de uma irrigação por inundação ou de um evento simples como uma chuva intensa".

$\mathrm{Na}$ Austrália, o efeito hardsetting ocorre em horizontes superficiais (A) e subsuperficiais (E, EB,BE e B) (Mullins et al., 1990; Chartres et al., 1990), com regimes de umidade xéricos e ústicos (Franzmeier et al., 1996). Os solos com horizontes hardsetting recobrem cerca de $23 \%$ da superfície daquele país (Mullins et al., 1999) mas, provavelmente, mais solos podem apresentar propriedades hardsetting em superfície ou tornar-se hardsetting sob cultivo.

Em termos de distribuição mundial, os solos com comportamento hardsetting ocorrem nas regiões tropicais áridas, semi-áridas e mediterrâneas (Mullins, 1999). Tratase de uma propriedade de solo comum sob condições climáticas de períodos secos e úmidos alternados (Chartres et al., 1990).

Estima-se que cerca de $12 \%$ dos solos da Zâmbia estão no grupo que têm sido identificados como hardsetting (Mullins et al., 1987). Alguns pesquisadores afirmam que muitos solos na África e outras regiões, também podem ser caracterizados como hardsetting (Mullins et al., 1987, 1990; Young, 1992). Mullins et al. (1990) comenta que Dregne em seu trabalho "Soils of Arid Regions" realizado em 1976, fez referência a solos da região nordeste do Brasil que, provavelmente, teriam comportamento similar. Alfisols (Mullins, 1999), Luvisols, Planosols e Solonetz (Mullins et al., 1990) são classes de solos em que foram identificadas características hardsetting.

O uso do termo hardsetting como atributo diagnóstico limitou-se ao sistema de classificação de solos da Austrália (Northcote, 1979), porque os solos com esse caráter não eram descritos, no campo, com segurança. Quando os levantamentos ocorriam no período em que o solo estava úmido, o comportamento hardsetting não era observado. A 
natureza ambígua do comportamento indicou que o designativo apresentava limitações para ser ncorporado a outros sistemas taxonômicos (Butler, 1980; Harper \& Gilkes, 1994) e não permitiu a ampliação do uso do mesmo. Por outro lado, hardsetting é reconhecido internacionalmente e amplamente utilizado na descrição dos solos da Austrália e de outros países de clima tropical (Isbell, 1996).

\subsection{Mecanismos relacionados à gênese dos solos com caráter coeso}

A evolução dos solos dos tabuleiros foi associada a distintos processos de transformação de Latossolos, considerados os primeiros solos da cobertura pedológica (Ribeiro, L.P., 2001). O primeiro modelo propõe que a cobertura pedológica foi entalhada, gerou vertentes onde se estabeleceram solos com horizonte B textural (ou apenas com gradiente textural como Argissolos amarelos e Acinzentados), e finaliza com os solos influenciados pela presença do lençol freático, nas partes baixas da paisagem. Quando os entalhamentos atingem o embasamento cristalino ocorrem outras classes como Cambissolos e solos com presença de sais solúveis. Outra forma de transformação desses Latossolos estaria ligada à presença de depressões fechadas na cobertura pedológica (Ucha, 2001; Carvalho, 2001). Essas depressões seriam formadas por processos de reativação de falhamentos (neotectônica) e diaclasamentos no embasamento cristalino, e apresentariam comportamento hidrodinâmico diferenciado, o que originaria um novo padrão de distribuição de solos. Da borda para o centro das depressões ocorreria a seqüência: Latossolo - Argissolo - Argissolo Acinzentado Spodossolo (Ucha, 2001; Ribeiro, L.P., 2001).

A gênese dos horizontes coesos ainda é um assunto polêmico, estando associada a vários processos, dentre os quais: à perda do plasma argiloso das camadas superficiais do solo para as camadas subjacentes, processo este denominado argiluviação; à presença de compostos orgânicos pouco polimerizados; à forte instabilidade estrutural; à presença de sílica secundária, ferro e argila dispersa nos microporos; e, ao adensamento por dessecação resultante da alteração da estrutura do solo pela alternância de ciclos de umedecimento e secagem (Ribeiro, 1986; Ponte \& Ribeiro, 1990). Esta última hipótese 
se baseia no pressuposto de que, durante o período seco, os agentes cimentantes seriam desidratados e a matriz argilosa consolidada a ponto de promover o adensamento, e que, durante o período úmido, os agregados destruídos, devido ao aumento da pressão de ar no seu interior. É provável, no entanto, que a maioria desses processos ocorra simultaneamente, e que a intensidade com que as camadas coesas sejam formadas esteja relacionada às variações climáticas e morfopedológicas existentes nas diferentes unidades geoambientais que compõem os tabuleiros costeiros (Ribeiro, 1998).

Em estudo mais recente, Araújo Filho et al. (2001) também associaram a coesão dos solos a causas múltiplas e inter-relacionadas. Um delas seria à presença de sílica e outros aluminossilicatos, que poderiam atuar como agentes cimentantes temporários, no período de secamento do solo. Nesse período ocorreria o processo de polimerização e precipitação da sílica e dos outros constituintes sílico-aluminosos amorfos, e a máxima expressão da coesão. No período úmido, por outro lado, a despolimerização daqueles elementos seria responsável pela condição de friabilidade do material. A grande rigidez que os horizontes coesos atingem na época seca também poderia estar relacionada com a força de adesão das ligações covalentes estabelecidas entre a os elementos cimentantes com as superfícies dos minerais (grupos $\mathrm{SiOH}, \mathrm{Al}-\mathrm{OH}$ ). Um outro fator considerado seria o adensamento natural do material que constitui os horizontes coesos, originado do acúmulo de materiais finos e do arranjamento massivo das partículas, que incrementaria a porosidade fina, restringiria a permeabilidade e favoreceria a precipitação dos agentes cimentantes temporários.

\subsection{Mecanismos relacionados à gênese dos solos com comportamento hardsetting}

Dois diferentes processos foram propostos para explicar o incremento de resistência em solos hardsetting, durante o secamento: i) o incremento do estresse efetivo, que resulta de um incremento de potencial mátrico da água no solo, quando o solo seca; e ii) a precipitação de sais solúveis nas zonas de contato entre agregados e/ou partículas (Mullins \& Panayiotopoulos,1984; Mullins et al., 1987; Mullins, 1999). O primeiro processo ocorre em todos os solos, nas etapas iniciais do secamento, antes que 
a água entre as partículas ou agregados tenha sido substituída por ar. O segundo processo somente ocorre em solos que liberam alguns sais solúveis, durante o umedecimento. Desta maneira, o processo hardsetting resulta do processo (i) com uma contribuição do processo (ii), para alguns solos.

A dispersão das argilas, associada ou não à presença de sódio, também é um

processo que determina o aparecimento do comportamento hardsetting. Como a sodicidade leva à instabilidade estrutural, muitos solos sódicos são hardsetting. O tipo de mineral de argila, a distribuição granulométrica das partículas na fração argila, e a geometria da superfície e características das cargas determinam o comportamento físico da fração argila e também influenciam a dispersibilidade de um solo (Mullins, 1999).

Chartres et al. (1990) argumentam que o desenvolvimento de resistência não é um fenômeno puramente físico (Mullins et al., 1987) e que a cimentação química teria um papel fundamental nesse processo. Ultimamente tem-se reconhecido que, nos solos hardsetting, os efeitos de agentes químicos cimentantes temporários somam-se aos efeitos do potencial mátrico ("estresse efetivo"), aumentando a resistência por ocasião do secamento (Franzmeier et al., 1996). Quando a cimentação química complementa os mecanismos físicos como parte do processo hardsetting, a sílica pode ser precipitada ou imobilizada de várias maneiras: i) pela combinação de sílica com íons AlOH para formar aluminossilicatos cristalinos ou alofanas e imogolitas pobremente ordenadas; ii) pela combinação de Si com óxidos de ferro, tais como goethita e ferrihydrita, as quais são associadas às superfícies das argilas criando complexos argila-óxido-sílica-óxidoargila; e iii) pela adsorção de sílica por hidróxidos de Al para formar pontes -Al-O-Si(Franzmeier et al., 1996). O fenômeno de age-hardening dos agregados do solo (Dexter et al., 1988) também evidencia o papel de ligações químicas no desenvolvimento da resistência, independente do potencial mátrico.

\subsection{Características dos solos coesos}

As características dos solos coesos refletem sua origem a partir de depósitos sedimentares do período Terciário (Grupo Barreiras) de materiais argilosos, argilo- 
arenosos ou arenosos, sempre bastante meteorizados. A mineralogia da fração argila tem mostrado que a caulinita é o mineral dominante, e a fração areia é constituída essencialmente por quartzo (Jacomine, 1996; Rezende, 2000). Em função do material de origem, os teores de $\mathrm{Fe}_{2} \mathrm{O}_{3}$ (ataque com $\mathrm{H}_{2} \mathrm{SO}_{4}$ ) são inferiores a $80 \mathrm{~g} \mathrm{~kg}^{-1}$, com predomínio de goethita, o que confere as cores amareladas típicas, geralmente brunoamareladas, tendendo muitas vezes para cores mais pálidas, bruno-amarelado claro, bruno claro acinzentado ou bruno no matiz 10 YR, com valores 5 e 6 e cromas entre 3 e 6 (Ribeiro, M.R., 2001). Uma característica comum desses solos é o valor Ki elevado (normalmente de 1,7 a 2,0), quando comparado aos valores geralmente observados nos Latossolos e Argissolos, em função da pequena quantidade de óxidos de ferro e alumínio, e da presença dominante de caulinita.

Os horizontes coesos dos solos não apresentam organização estrutural nítida da massa do solo, o que geralmente leva à formação de uma estrutura maciça, com graus variáveis de coesão (moderadamente coesos a coesos), e média aritmética de densidade do solo de 1,5 a 1,8 $\mathrm{kg} \mathrm{dm}^{-3}$ (CEPLAC, 1998; EMBRAPA, 1999; Ribeiro, M.R., 2001; Araujo Filho et al., 2001). Os limites de textura descritos variam de franco-argiloarenosa a muito argilosa (CEPLAC, 1998; Rezende, 2000), sendo o grau de coesão proporcional ao aumento do teor de argila (Ribeiro, M.R., 2001). Os horizontes coesos não devem ser confundidos com fragipãs, que também tem altos níveis de coesão, mas apresentam quebradicidade moderada, rompendo-se subitamente quando submetidos à pressão entre o polegar e o indicador. Os coesos passam por lenta deformação, quando examinados úmidos (Jacomine, 2001; Ribeiro, M.R., 2001).

Horizontes coesos de solos apresentam-se dessaturados de bases, ácidos (pH em água normalmente entre 4,0 e 5,0) e, normalmente, atingem valores elevados de alumínio trocável. Em menor proporção são encontrados solos distróficos, sendo raros os registros de solos eutróficos (zona semi-árida) (Jacomine, 1996; 2001; Rezende, 2000). O teor em carbono, mesmo nos solos argilosos sob mata, raramente se eleva acima de $15 \mathrm{~g} \mathrm{~kg}^{-1}$ (Ribeiro, L.P., 2001; Jacomine, 2001). 


\subsection{Características dos solos hardsetting}

Tennant et al. (1992) afirmaram que as propriedades físicas e químicas de solos com comportamento hardsetting caracterizados por Northcote (1979) no Oeste da Austrália, refletem sua origem a partir de superfícies erosionais de antigas lateritas e de variações climáticas, ocorridas no período Terciário. Os períodos cíclicos de umidade e seca (muito semelhantes ao clima atual), teriam contribuído para o desenvolvimento de uma superfície de solos com alta densidade e tendências ao encrostamento, além da subsuperfície compacta e maciça.

Os solos hardsetting não apresentam estruturação evidente (apedal), justificada pela pouca quantidade de argila presente, a qual determina os processos de contração e fendilhamento da massa do solo, observados durante o secamento. O comportamento hardsetting requer que o solo seco apresente uma elevada resistência, o que deve acontecer se os teores de argila e silte forem suficientes para ligarem os grãos de areia, de modo que esses grãos se mantenham unidos numa rígida matriz (Mullins et al., 1987; Lamotte et al.,1997). Desta maneira, a maioria dos solos descritos com esse caráter apresentam textura franco-arenosa, franca e argila-arenosa, embora tenham sido identificados alguns com textura areia franca, argila-arenosa e argilosa (Mullins et al., 1990; Mullins, 1999). Os valores de densidade do solo observados são, normalmente, bastante elevados (Harper \& Gilkes, 1994). Na maioria dos solos hardsetting a mineralogia da fração argila é dominada por caulinitas ou micas hidratadas (ilitas) que, praticamente, não desenvolvem fendas estruturais durante o secamento, quando contidas na matriz do solo (Norrish \& Pickering, 1983). O comportamento hardsetting é, predominantemente, observado em solos com baixas concentrações de matéria orgânica (Mullins et al, 1990), tipicamente menor que $20 \mathrm{~g} \mathrm{~kg}^{-1}$. 


\subsection{Problemas relacionados aos solos com elevada resistência, quando secos}

Os solos que desenvolvem elevada resistência, durante o secamento, são uma fonte de limitações físicas, cujos efeitos podem ser imperceptíveis ou devastadores em relação ao preparo e desenvolvimento das culturas. Mullins et al. (1987; 1990) indicaram uma gama de problemas agronômicos associados aos solos com esse comportamento, incluindo o tempo restrito para o preparo do solo e o incremento dos impedimentos físicos para o adequado desenvolvimento radicular. A elevada resistência desses solos, quando secos, traz sérias implicações ao crescimento das raízes, porque a resistência do solo à penetração (RP) normalmente excede os $3 \mathrm{MPa}$, antes que o solo tenha atingido o ponto de murcha permanente (- 1,5 $\mathrm{MPa}$ de potencial mátrico). $\mathrm{O}$ valor de $3 \mathrm{MPa}$ é indicado como suficiente para impedir severamente ou parar o crescimento radicular e limitar a emergência de hipocótilos (Mullins, 1997). Weaich et al. (1992a) e Masle \& Passioura (1987) já haviam demonstrado como o efeito hardsetting impede a emergência dos hipocótilos e como o mesmo poderia ser teoricamente prognosticado. Em solos coesos do nordeste brasileiro, Rezende (2000) salientou o efeito negativo do aumento da resistência dos horizontes coesos do solo no desenvolvimento do sistema radicular da laranjeira, sobretudo o das raízes pivotantes.

Para o crescimento das raízes, o incremento da resistência é particularmente importante durante o secamento dos solos hardsetting e coesos. Nessa situação, as raízes não encontram caminhos para se desenvolverem, devido à ausência de fendas estruturais. Alguns solos estudados por Mullins et al. (1987) desenvolveram uma resistência à penetração acima de $3 \mathrm{MN} \mathrm{m}^{-2}$, antes mesmo de terem secado a um potencial de -0,1 MPa. Ley et al. (1995) encontraram uma RP igual ou maior a $2 \mathrm{MPa}$ em alguns solos da Nigéria, quando foram secados a um potencial matricial de apenas 0,1 MPa. Resultados similares foram obtidos para solos hardsetting do Reino Unido (Young et al., 1991), Austrália (Mullins et al., 1992b) e Tanzânia (Mullins, 1997), e solos coesos do nordeste do Brasil (Santos, 1992; Nacif, 1994; Rezende, 2000; Giarola et al., 2001). 
Os solos com horizontes hardsetting e coesos estão sujeitos a prejuízos pelo preparo realizado fora de uma estreita faixa de conteúdo de água. Quando o preparo desses horizontes é feito com o solo seco, tendem a quebrar-se em blocos grandes que, após a redução do tamanho dos mesmos, pode levar àformação de uma camada de cultivo pulverizada bastante propícia ao selamento superficial e à enxurrada (Tisdall \& Adem, 1986). Já o preparo realizado com o solo úmido, mobiliza uma grande proporção de silte e argila desses horizontes, que pode reduzir a infiltração, assim como produzir uma superfície endurecida através da qual as plântulas são incapazes de penetrar (Tisdall \& Adem, 1986). O preparo em solo muito úmido, além de resultar em compactação, também pode mobilizar algum agente cimentante, que propicie o endurecimento do solo durante o secamento.

Segundo (Mullins, 1997) e Ribeiro, M.R. (2001), os horizontes hardsetting e coesos limitam o crescimento do sistema radicular das culturas e, assim, a produtividade, porque reduzem a infiltração da água no solo, promovendo falta de aeração, aumento de escoamento superficial da água da chuva ou irrigação, e o acúmulo de água em depressões. A redução do crescimento do sistema radicular contribui para o aumento da deficiência de água em virtude do menor volume de solo explorado. Sob irrigação, é possível superar algumas destas limitações, mas o colapso estrutural pode levar a uma restrição na aeração das raízes e na entrada de água (Mullins, 1997; Rezende, 2000). No caso dos solos com horizontes coesos, as limitações são mais graves nos mais argilosos, com textura argilo-arenosa ou mais fina no horizonte coeso. Nestes casos, o sistema radicular é limitado pela dureza, quando o solo está seco, e pela falta de aeração, no período chuvoso. Nos perfis mais arenosos, o simples aprofundamento da umidade reduz a resistência à penetração das raízes, sem que haja excesso de umidade (Ribeiro, M.R., 2001).

A raízes que crescem em solos hardsetting e coesos, e que, simultaneamente, os secam, aumentam, progressivamente, o impedimento mecânico do solo e, consequentemente, reduzem a taxa de crescimento radicular. Entretanto, onde o perfil for umedecido e o impedimento mecânico do solo reduzido, as raízes poderão recuperar rapidamente o crescimento. Dessa maneira, o efeito total na distribuição das raízes no 
perfil do solo dependerá do modelo de distribuição das chuvas local e do grau de umedecimento do mesmo. O efeito das restrições causadas pelo endurecimento do solo no crescimento radicular e, consequentemente, no desenvolvimento das culturas, foi modelado para solos com horizonte hardsetting por Bradley e Crout, usando RP versus características de sucção mátrica em solos da Tanzânia (Mullins, 1997).

\subsection{Identificação dos solos coesos}

O estudo realizado por Oliveira et al. (1968) deu início à caracterização pormenorizada do adensamento subsuperficial em áreas de tabuleiros. Anos depois, Oliveira \& Melo (1970) concluíram que a utilização agrícola desses solos era limitada pelas condições físicas do subsolo e destacaram a diminuição da aeração e a baixa permeabilidade, em decorrência do adensamento que limitava a penetração das raízes das plantas. Jacomine et al. (1975), Anjos (1985), Fonseca, (1986), Silva (1989; 1996) e EMBRAPA (1995), deram continuidade à identificação e caracterização de solos com caráter coeso em várias regiões do Brasil, sem, no entanto, estabelecerem critérios quantitativos para a identificação dos mesmos.

No Brasil, a identificação dos horizontes com caráter coeso tem sido feita qualitativamente, através da análise morfológica do perfil. Tais solos, quando secos, apresentam resistência à penetração elevada do martelo pedológico, tornando-se friáveis, quando umedecidos. Esse procedimento dificulta a identificação do caráter com base em critérios seguros, que permitam a extensão do uso do mesmo às demais regiões do país. A falta de estudos pormenorizados sobre esse comportamento, também impede que se defina se esses horizontes estão relacionadas com as propriedades do solo ou com as modificações do solo impostas pelo manejo ou, ainda, com as condições climáticas prevalecentes na área.

Como tentativa de normatização do critério de avaliação dos graus de coesão, EMBRAPA (1979a) estabeleceu padrões de referência para a identificação da coesão dos solos a partir das características observadas nos Latossolos Amarelos do Grupo Barreiras, da faixa dos Tabuleiros Costeiros, região Nordeste do Brasil. O termo coeso 
seria, nessa oportunidade, utilizado provisoriamente, até que se encontrasse outro mais adequado para definir esse comportamento.

A definição dada por Ribeiro (1991) para o caráter coeso, associada a valores de densidade do solo, foi sugerida para uso a partir da IV Reunião de Classificação, Correlação e Aplicação de Levantamentos de Solos (EMBRAPA, 1995), além da criação de um sufixo que indicaria o caráter coeso e o incorporaria, como atributo distintivo de classe, ao sistema de classificação de solos do Brasil. A organização de uma definição mais detalhada dos graus de coesão também foi sugerida naquela oportunidade.

O atual Sistema Brasileiro de Classificação de Solos (EMBRAPA, 1999) não apresenta uma definição objetiva para o designativo "coeso" que permita a identificação segura desse comportamento no campo, e restringe o uso do mesmo apenas para a classe dos Latossolos Amarelos originários dos sedimentos do Grupo Barreiras. Permanece, ainda, a necessidade de definir com maior clareza, parâmetros que caracterizem a camada coesa e sua localização no perfil e, ainda, de estabelecer critérios para medir o grau de coesão dos solos, definindo solos coesos com graus variáveis de coesão, de modo a orientar medidas de manejo para cada situação (Nogueira, 1996).

\subsection{Identificação dos solos hardsetting}

O reconhecimento de horizontes hardsetting se apoiava, principalmente, em avaliações qualitativas de atributos morfológicos do solo. Mullins et al. (1987) mencionavam que as observações de campo de perfis de solo secos eram fundamentais para caracterizar a ausência de estrutura e, ainda, testar o comportamento de pequenos fragmentos do solo seco, quando imersos em água (onde eles devem rapidamente enfraquecer-se e desintegrar-se).

Posteriormente, Mullins (1997) sugeriu que a identificação no campo de um horizonte hardsetting deveria, também, levar em conta medidas de resistência do solo, pois o valor de resistência contido na definição de hardsetting era arbitrário e baseado na experiência. Em horizontes hardsetting, numa mesma variação de umidade, a variação 
da resistência do solo seria muito maior do que num solo com estrutura estável (Mullins et al., 1992a).

Vários estudos demonstram que a resistência à penetração é uma medida útil para o estudo da resistência de solos com horizontes ou camadas hardsetting (Mullins et al., 1992a; Ley \& Laryea, 1994), uma vez que, com o secamento, esses se tornam extremamente duros, impedindo o crescimento e funcionamento das raízes. A curva de resistência do solo pode ser usada para indicar a rapidez com que a resistência aumenta com o decréscimo da umidade. Outros critérios diagnósticos no estudo de solos com comportamento hardsetting são apresentados por Mullins (1997).

Becher et al., (1997) propuseram um índice para identificar solos com características hardsetting, utilizando a máxima resistência obtida e um parâmetro descritivo da sensibilidade de variação da resistência com a umidade (I). Os autores sugerem a relação $\mathrm{RP}_{\max } / \mathrm{I}$ para descrever a taxa de variação da resistência com a umidade do solo, e sua magnitude poderia ser indicada para identificação dos solos com características hardsetting. A importância da quantificação da taxa de variação da resistência com a umidade deve-se ao fato de que destas taxas podem resultar em ocorrência de resistências impeditivas ao crescimento das plantas sob umidades maiores que o ponto de murcha permanente (Weaich et al., 1992b; Hall et al., 1994; Ley et al., 1995). 


\section{SIMILARIDADES ENTRE O CARÁtER COESO DOS SOLOS E O COMPORTAMENTO HARDSETTING : ESTUDO DE CASO}

\section{Resumo}

O termo coeso é utilizado, no Brasil, para distinguir horizontes superficiais e subsuperficiais de solos que apresentam consistência dura, muito dura ou extremamente dura, quando secos, e friável, quando úmidos. Solos australianos com características similares foram identificados como hardsetting. Muitos solos da África e de outras regiões semi-áridas podem ser caracterizados como hardsetting, segundo vários pesquisadores. O objetivo deste trabalho foi testar a hipótese de que solos com caráter coeso, identificados sobre os sedimentos do Terciário, na região nordeste do Brasil, apresentam propriedades morfológicas e físicas similares aos solos hardsetting. O estudo foi realizado em um Latossolo Amarelo Coeso, localizado em Cruz das Almas (BA), sob floresta secundária. Durante o período de secamento do solo, foram caracterizadas as mudanças morfológicas ocorrentes no perfil e, ainda, realizadas medidas da resistência do solo à penetração em horizontes não-coeso (A1) e coeso (AB1). Os resultados indicaram que os parâmetros morfológicos e físicos do horizonte coeso foram similares àqueles utilizados para definir o comportamento hardsetting.

\section{Summary: "Similarities between brazilian coeso soils and hardsetting soils: a case study"}

The term "cohesive" has been used in Brazil to distinguish sub-surface soil horizons that have hard, very hard or extremely hard consistency when the soil is dry, 
and friable when the soil is wet. Australian soils with similar behavior were identified as hardsetting. Researchers have indicated that many soils in Africa and other semi-arid regions can also be characterized as hardsetting. Based on the definition and characteristics of the hardsetting soils, it is believed that "cohesive" soils of the Low Coastal Tablelands, the northeastern region of Brazil have similar behavior. The aim of this work was to test the hypothesis that "cohesive" soils have similar morphological and physical properties similar to the hardsetting soils. The study was carried out in a "cohesive" Yellow Latosol, located in Cruz das Almas (BA), under secondary forest. During a soil-drying period, morphological analysis of the soil profile and measurements of the soil resistance to penetration were made in normal and cohesive horizons. The results indicated that both the morphological and physical parameter of the cohesive soil were similar to those used to identify hardsetting soils.

\subsection{Introdução}

O termo coeso é empregado, no Brasil, para distinguir horizontes minerais subsuperficiais de solos que apresentam consistência dura, muito dura ou até extremamente dura quando secos, e friável, quando úmidos (Ribeiro, 1991; EMBRAPA, 1995; Jacomine, 1996). Solos com essas características foram observados, pela primeira vez, na década de 50, no município de Campos (RJ), na faixa de domínio dos Tabuleiros Costeiros. Anos depois, foram identificados nos vales do Paraíba do Sul e do Tietê (SP) e em cobertura do Terciário em Minas Gerais (Jacomine, 1996). Diversos pesquisadores, dentre os quais se destacam Jacomine et al. (1975), Anjos (1985), Fonseca (1986), Silva (1989), EMBRAPA (1995) e Silva (1996), deram continuidade à identificação e caracterização de solos com caráter coeso em várias regiões do Brasil, sem, no entanto, estabelecerem critérios para a identificação desses solos.

Em outras partes do mundo, também tem sido reconhecida uma forma particular de comportamento de solo em que este se torna duro, quando seco, a ponto de dificultar ou mesmo impossibilitar o desenvolvimento das culturas, e cessa esse impedimento no 
momento em que se torna úmido novamente. Esse comportamento, na Austrália, foi identificado, mapeado e denominado “hardsetting” (Northcote et al., 1975).

O termo hardsetting vem sendo utilizado para caracterizar um tipo de comportamento de solo (intrínseco ou adquirido por uso e manejo), bem como para tipificar horizontes e solos. Solos com esse comportamento são aqueles que, quando submetidos a um regime de saturação hídrica plena, esboroam-se subitamente e, quando secos, apresentam uma massa sem estrutura e endurecida, que se renova naturalmente mesmo depois de o solo ter sido preparado para o cultivo (Mullins, 1999). Embora muitos solos apresentem essa característica, somente aqueles que se tornam duros o suficiente para dificultar ou mesmo impossibilitar o cultivo foram classificados como hardsetting. No Brasil, o termo coeso vem sendo empregado para solos e, ou, horizontes duros e muito duros, formados a partir de sedimentos da Formação Barreiras, sem considerar qualquer restrição ao uso dos solos, imposta pela resistência oferecida pelos horizontes.

Os solos com comportamento hardsetting são de ocorrência comum sob climas que apresentam alternância entre períodos secos e úmidos (Chartres et al., 1990; Mullins et al., 1990; Young, 1992). Esse caráter é observado em horizontes superficiais (cultivados e não cultivados) e subsuperficiais (não cultivados) (Franzmeier et al., 1996). Os limites de textura variam de areia a argila-arenosa e a mineralogia da fração argila é dominada por caulinitas ou micas hidratadas (ilitas) (Norwish \& Pickering, 1983). É, predominantemente, observado em solos com baixos teores de matéria orgânica, normalmente inferiores a 2\% (Mullins et al., 1990).

A ocorrência dos solos com caráter coeso está associada, dominantemente, a regiões de climas que apresentam estações secas e úmidas definidas (Jacomine, 1996). De acordo com Fonseca (1986) e EMBRAPA (1999), o caráter coeso ocorre na altura dos horizontes $\mathrm{AB}$ e, ou, BA, e até parte do Bw. Estes solos apresentam baixa saturação por bases, teores de $\mathrm{Fe}_{2} \mathrm{O}_{3}$ (pelo $\mathrm{H}_{2} \mathrm{SO}_{4}$ ) menores que $8 \%$ e índice $\mathrm{Ki}$ de 1,7 ou maior, isto é, são de mineralogia caulinítica (EMBRAPA, 1999).

Para o reconhecimento e identificação de horizontes com caráter hardsetting, Mullins (1997) admite serem as observações de campo em perfis secos uma etapa 
fundamental. Além dessas observações, esse autor apregoa que uma identificação segura desses horizontes só pode ser obtida, quando se consideram medidas de resistência do solo, pois os valores de resistência constantes na definição de hardsetting são arbitrários e baseados na experiência de campo do pesquisador, além do fato de que, quando úmidos, esses horizontes não apresentam endurecimento. Estudos anteriores já haviam demonstrado que a resistência do solo à penetração era uma medida útil para a caracterização e análise desse caráter de solo (Mullins et al., 1992a; Ley \& Laryea, 1994).

Alguns pesquisadores afirmam que muitos solos da África e de outras regiões semi-áridas também podem apresentar comportamento hardsetting (Mullins et al., 1987). Mullins et al. (1990) comentam que Dregne em seu trabalho 'Soils of Arid Regions" realizado em 1976, fez referência a Alfisols da África e da região nordeste do Brasil que, provavelmente, apresentariam esse atributo. Com base nessas informações, estabeleceu-se a hipótese de o caráter coeso observado e descrito em solos formados sobre os sedimentos da Formação Barreiras (Terciário), na região dos Tabuleiros Costeiros, ser similar ao comportamento hardsetting.

O objetivo desta pesquisa foi avaliar, por meio de parâmetros morfológicos e físicos de um Latossolo Amarelo Coeso, possíveis similaridades entre o caráter coeso definido no Brasil e o hardsetting identificado e mapeado na Austrália.

\subsection{Material e Métodos}

\subsubsection{Solo e local de amostragem}

O estudo foi realizado em perfil de Latossolo Amarelo Coeso argissólico álico, sob floresta secundária, tido como representativo de classe e formado a partir de sedimentos argilo-arenosos da Formação Barreiras (Terciário), município de Cruz das Almas (BA). A região apresenta clima subúmido segundo a classificação de Thornthwaite, com tendência a semi-árido. A escolha de perfil sob floresta estacional semidecidual teve o intuito de eliminar a variável uso do solo. 


\subsubsection{Critérios adotados para a análise das similaridades}

Os atributos utilizados para avaliar as similaridades entre o caráter coeso e o comportamento hardsetting foram os seguintes:

Atributos morfológicos:

- consistência dura ou extremamente dura, quando secos, apresentando-se sem estrutura definida (Weaich et al., 1992b; Mullins, 1997);

Atributos físicos:

- variação da textura argilo-arenosa a franco-argilo-arenosa (Mullins et al., 1990; Mullins, 1997);

- incremento acentuado da resistência do horizonte, numa faixa estreita de teor de água - comportamento da curva de resistência do solo (Mullins et al., 1987);

Atributos complementares:

- maior resistência oferecida pelo horizonte ao exercer uma pressão com o dedo indicador (Mullins et al., 1990);

- presença de fendas longitudinais ocasionais, espaçadas de pelo menos $10 \mathrm{~cm}$ (Mullins, 1997);

- $\quad$ pouca quantidade de argilas expansivas (Young, 1992);

- conteúdo de matéria orgânica inferior a 2 \% (Mullins, 1997);

\subsubsection{Metodologia de análise}

\subsubsection{Morfologia do perfil}

As descrições morfológicas foram realizadas uma vez ao dia, durante cinco dias, e, apenas no primeiro dia, o solo foi umedecido com pulverizador costal, até que adquirisse consistência friável. Tal procedimento permitiu avaliar as mudanças estruturais e as diferenças na consistência dos horizontes do perfil, quando este passou do estado úmido para o seco. Na descrição morfológica e determinação dos horizontes 
com caráter coeso, adotaram-se, respectivamente, as normas e definições constantes em Lemos \& Santos (1996), Jacomine (1996) e Ribeiro (1991).

\subsubsection{Elaboração das curvas de resistência do solo}

Dentre os testes sugeridos por Mullins (1997) para caracterizar o comportamento hardsetting, selecionourse a resistência à penetração (RP) em diferentes umidades, por se tratar de medida de fácil obtenção no campo. As medidas de resistência foram obtidas da seguinte forma: o perfil do solo foi homogeneamente umedecido com o auxílio de pulverizador costal, de forma que os dois horizontes selecionados (A1 e AB1) adquirissem consistência friável. Cada um dos horizontes foi, então, subdividido em dez partes. Em cada uma das partes foram realizadas 20 leituras de resistência à penetração (RP). Cada parte desses horizontes foi analisada a cada meio período do dia (manhã e tarde), durante cinco dias e, simultaneamente, coletou-se uma amostra composta para a determinação da umidade gravimétrica (U). A partir das medidas de RP em diferentes umidades, foram geradas as curvas de resistência do solo (CRS) dos dois horizontes (não-coeso e coeso). As leituras de RP foram realizadas com um penetrômetro cônico, modelo Solotest S-310, com cone de aço inox de $30^{\circ}$, diâmetro de base de 4,8 mm e haste com 2,5 cm de comprimento. As CRS dos horizontes foram ajustadas em relação à umidade gravimétrica (U), utilizando-se o modelo proposto por Busscher (1997):

$$
\mathrm{RP}=a \mathrm{U}^{b}
$$

Na equação (1), RP é a resistência à penetração (MPa), U é a umidade do solo

(kg. $\left.\mathrm{kg}^{-1}\right)$. Os coeficientes $a$ e $b$ são os parâmetros do modelo obtidos através de ajuste não linear utilizando-se o método de Gauss-Newton (SAS Institute, 1991).

\subsubsection{Análises complementares}

Em cada horizonte do perfil do solo, foram coletadas amostras de cerca de $500 \mathrm{~g}$ para realização de análises físicas e químicas complementares. 
A análise granulométrica foi realizada pelo método de Bouyoucos (EMBRAPA, 1979b), sendo as areias separadas por tamisação em cinco frações. Para determinar a argila dispersa em água, utilizourse o mesmo método da análise granulométrica, porém sem a adição do dispersante químico. A densidade do solo $\left(\mathrm{D}_{\mathrm{s}}\right)$ foi obtida pelo método descrito por Blake \& Hartge (1986).

Cálcio, magnésio e alumínio trocáveis foram extraídos com solução de $\mathrm{KCl} 1 \mathrm{~N}$, segundo Vettori (1969) e EMBRAPA (1979b). A extração de fósforo, potássio e sódio foi realizada com solução contendo $\mathrm{H}_{2} \mathrm{SO}_{4} 0,025 \mathrm{~N}+\mathrm{HCl} 0,05 \mathrm{~N}$. A extração de $\mathrm{H}^{\dagger}+$ $\mathrm{Al}^{3+}$ foi feita com solução de acetato de cálcio $1 \mathrm{~N}$ a $\mathrm{pH} 7,0 . \mathrm{O} \mathrm{pH}$ foi determinado potenciometricamente, usando-se a relação 1:2,5 de solo:água; solo: $\mathrm{KCl} 1 \mathrm{~N}$ e $\mathrm{CaCh}_{2}$ 0,01 M. O carbono orgânico foi determinado segundo Vettori (1969) e EMBRAPA (1979b). Os óxidos $\mathrm{SiO}_{2}, \mathrm{Al}_{2} \mathrm{O}_{3}, \mathrm{Fe}_{2} \mathrm{O}_{3}, \mathrm{TiO}_{2}$ e $\mathrm{P}_{2} \mathrm{O}_{5}$ foram determinados após digestão com $\mathrm{H}_{2} \mathrm{SO}_{4}$ 1:1, conforme Vettori (1969) e EMBRAPA (1979b).

\subsection{Resultados e Discussão}

O perfil estudado apresentava sequiência de horizontes Oo, A1, A2, AB1, AB2, $\mathrm{BA}, \mathrm{Bw} 1$ e Bw2, sendo muito profundo e, eventualmente, com mais subdivisões no Bw. Como se tratava de perfil sob floresta, constatoutse um horizonte orgânico $(\mathrm{O})$ de $2 \mathrm{~cm}$ de espessura, constituído por restos vegetais pouco decompostos (Tabela 1).

O horizonte superficial A1 apresentou coloração bruno-escura ou brunoacinzentada muito escura (10 YR 3,5/2), quando úmido, passando a bruno-amarelado escuro (10 YR 4/4), quando seco. Os demais horizontes até os $130 \mathrm{~cm}$ de profundidade tinham coloração bruno-amarelada (10 YR 5/4), quando seco, e bruno-amarelado-escura (10 YR 4/4), quando úmido. O horizonte Bw2 tinha cor úmida bruno-amarelada (10 YR $5 / 8)$. 
Tabela 1. Características morfológicas do Latossolo Amarelo Coeso em diferentes umidades.

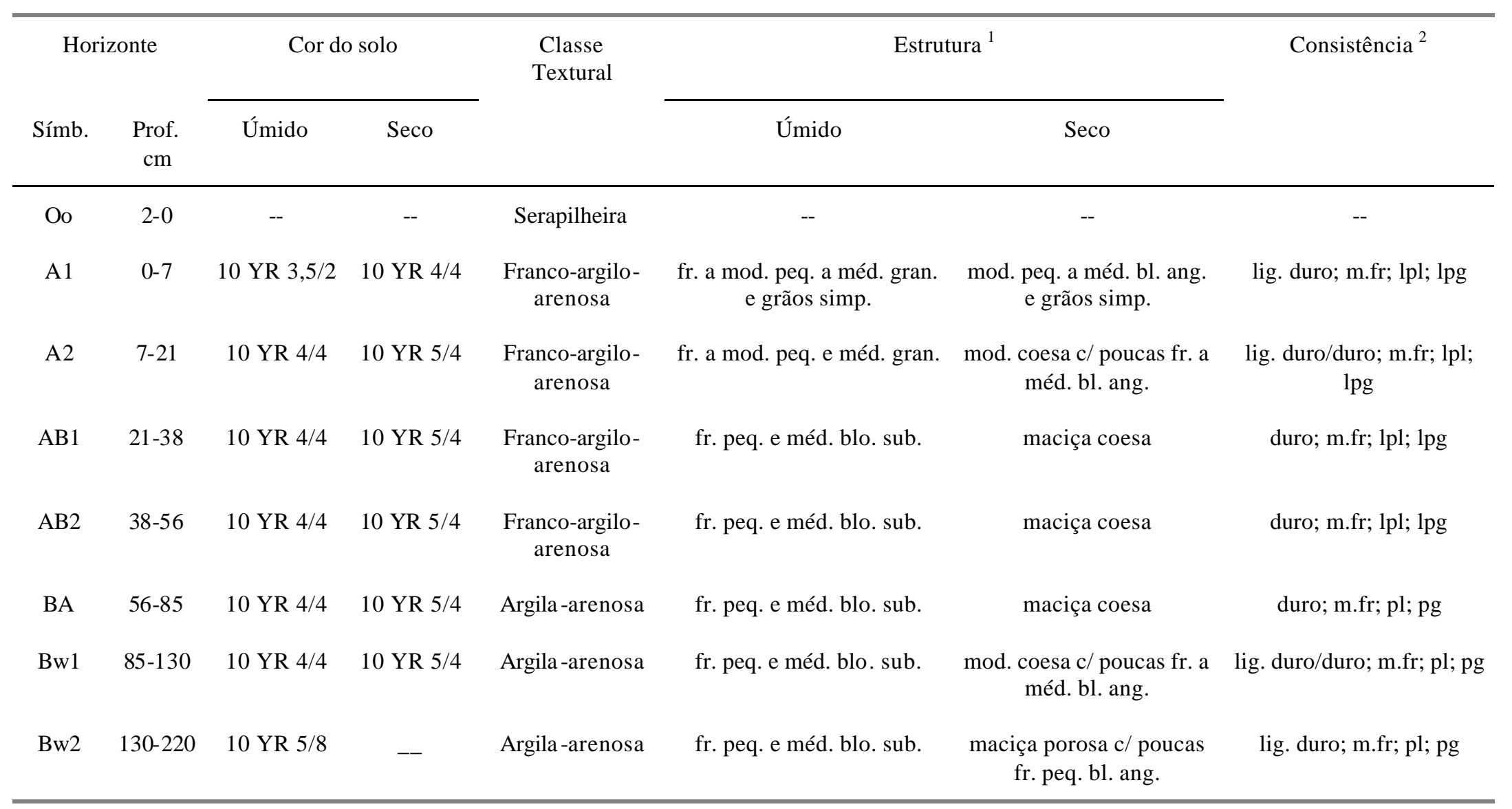

${ }^{1 .}$ fr. $=$ fraca mod. = moderada; peq. = pequena; méd. = média; gran. = granular; bl. = blocos; ang. = angulares; sub. = subangulares; simp. = simples.

${ }^{2}$ lig. = ligeiramente; $\mathrm{m} . \mathrm{fr} .=$ muito friável $; \mathrm{lpl}=$ ligeiramente plástico; $1 \mathrm{pg}=$ ligeiramente pegajoso; $\mathrm{pl} .=$ plástico; pg = pegajoso 
Foram observadas diferenças marcantes de consistência do solo, quais sejam: consistência muito friável e friável, quando úmido, e dura, quando seco, principalmente nos horizontes AB1, AB2 e BA, definindo o caráter coeso desses solos (Ribeiro, 1991; Jacomine, 1996). As mesmas diferenças de consistência observadas no solo estudado vêm sendo utilizadas para definir o caráter hardsetting (Mullins, 1997), indicando uma primeira similaridade morfológica entre eles.

A análise morfológica realizada em diferentes estados de umidade evidenciou que o maior grau de coesão apresentado pela massa do solo dos 21 aos $85 \mathrm{~cm}$ de profundidade somente foi observado quando o solo se encontrava seco (quarto dia de observação), sendo expresso pela estrutura maciça coesa (Tabela 1). A ocorrência desse tipo de estrutura dominando a maior parte do perfil vem sendo utilizada por Ribeiro (1991) como critério distintivo auxiliar na definição de volumes coesos e como característica morfológica associada aos horizontes hardsetting (McDonald et al., 1990; Mullins, 1997). No caso do perfil estudado, o uso da estrutura como critério distintivo de apoio é questionável, tendo em vista a modificação ocorrida com a variação da umidade do solo, comprovada pelos resultados apresentados na Tabela 1. Essa natureza ambígua da estrutura, utilizada também para definir o caráter hardsetting, já havia sido levantada por Harper \& Gilkes (1994). Segundo estes autores, o termo hardsetting teria um valor limitado para os sistemas de classificação, pois um dos objetivos desses sistemas seria classificar com base em observações e não em inferências (Butler, 1980).

A profundidade do adensamento, que expressa morfologicamente o caráter coeso (Tabela 1) ocorreu na mesma altura indicada nas descrições de Latossolos Amarelos coesos e outros solos não cultivados das áreas de Tabuleiro, realizadas por Fonseca (1986) e CEPLAC (1998). Em áreas de cultivo contínuo com cana-de-açúcar, o maior grau de coesão, comprovado pelo aumento da densidade do solo, foi constatado mais próximo à superfície, conforme as alterações promovidas pelo uso e manejo (Silva \& Ribeiro, 1992). Silva et al. (1998) relacionaram esse aumento da coesão com a destruição dos agregados (peds e poros de empacotamento) e com a redução dos teores de matéria orgânica, promove ndo não só uma drástica queda da porosidade total e da condutividade hidráulica, mas também um aumento da densidade do solo dos horizontes 
superficiais. Essas modificações estabeleceram, então, o caráter coeso adquirido por uso e manejo e não geneticamente herdado, como no caso dos horizontes subsuperfciais adensados sob floresta. Analogamente, o caráter hardsetting utilizado nas descrições dos solos australianos é tido como aquele herdado e também o que pode ser adquirido e potencializado pela interferência do homem (Mullins, et al., 1987).

Outra indicação de similaridade entre os horizontes coesos e os hardsetting foi obtida a partir da avaliação da resistência do solo no campo (Mullins et al., 1990). No perfil estudado, a face do horizonte coeso (AB1), quando seco, ofereceu resistência à deformação quando submetida à pressão exercida pelo dedo indicador.

Fendas longitudinais ocasionais (espaçadas de pelo menos $10 \mathrm{~cm}$ ), outra característica associada a hardsetting, não foram observadas no perfil estudado durante o período de realização do trabalho, mas eram visíveis em perfis do mesmo solo, mais secos, cultivados com mandioca e citros. A formação de fendas nesses solos cauliníticos, tidos como não expansivos, pode estar relacionada com a atividade de caulinitas de alto grau de desordem estrutural presentes na fração argila (Almeida, Kämpf \& Klamt, 1992). A relação molecular Ki (Tabela 2) e os resultados da análise de difração de raios X (não apresentados) confirmam o predomínio de caulinita na fração argila. Essa mesma mineralogia também é associada aos solos com caráter hardsetting (Norrish \& Pickering, 1983; Young, 1992).

Os resultados da análise granulométrica demonstram um aumento dos teores de argila total em profundidade, culminando com a formação de um hrizonte $\mathrm{Bw}$ argiloso aos $85 \mathrm{~cm}$ (mais de $40 \%$ de argila). Contrariamente, os teores de areia foram maiores nos horizontes superficiais (76 e $74 \%$ em A1 e A2, respectivamente), diminuindo à medida que aumentava a profundidade. Os limites de textura encontrados no solo estudado coincidem com os mencionados para os solos com caráter hardsetting, que variam de areia a argila-arenosa (Mullins et al., 1990; Mullins, 1997). 
Tabela 2. Composição granulométrica e Densidade do Solo do Latossolo Amarelo Coeso argissólico.

\begin{tabular}{|c|c|c|c|c|c|c|c|c|c|c|c|}
\hline \multicolumn{2}{|c|}{ Horizonte } & \multirow[t]{2}{*}{$\mathrm{D}_{\mathrm{s}}$} & \multicolumn{2}{|c|}{ Argila } & \multicolumn{5}{|c|}{ Areia $^{2}$} & \multirow{2}{*}{$\begin{array}{l}\text { Areia } \\
\text { Total }\end{array}$} & \multirow[t]{2}{*}{ Silte } \\
\hline Símbolo & Profundidade & & Total $^{1}$ & Natural & AMG & AG & $\mathrm{AM}$ & $\mathrm{AF}$ & AMF & & \\
\hline & $\mathrm{cm}$ & $\mathrm{g} \mathrm{cm}^{-3}$ & & & & & $\%$ & & & & \\
\hline A1 & $0-7$ & 1,39 & 22 & 4 & 2 & 22 & 29 & 19 & 4 & 76 & 2 \\
\hline $\mathrm{A} 2$ & $7-21$ & -- & 24 & 6 & 3 & 21 & 25 & 21 & 4 & 74 & 2 \\
\hline $\mathrm{AB} 1$ & $21-38$ & 1,57 & 26 & 8 & 3 & 19 & 23 & 23 & 5 & 73 & 1 \\
\hline AB2 & $38-56$ & -- & 32 & 13 & 3 & 18 & 20 & 20 & 6 & 67 & 1 \\
\hline BA & $56-85$ & -- & 38 & 18 & 2 & 17 & 19 & 17 & 5 & 61 & 1 \\
\hline Bw1 & $85-130$ & 1,53 & 40 & 0 & 2 & 15 & 20 & 17 & 5 & 59 & 1 \\
\hline Bw2 & $130-+$ & -- & 52 & 0 & 2 & 11 & 16 & 14 & 5 & 48 & 0 \\
\hline
\end{tabular}

${ }^{1} \mathrm{RT}$ (Relação Textural) = 1,6;

${ }^{2} \mathrm{AMG}=$ areia muito grossa; $\mathrm{AG}=$ areia grossa; $\mathrm{AM}=$ areia média; $\mathrm{AF}=$ areia fina; $\mathrm{AMF}=$ areia muito fina. 
Pela composição granulométrica verifica-se a predominância da fração areia na maior parte do perfil, exceto nos horizontes Bw1 e Bw2 (Figura 1). Uma matriz dominada por grãos de areia, em que a argila e o silte (material fino) podem funcionar como pontes de conexão dos grãos adjacentes ou mesmo como material ligado à superfície dos grãos individuais, é citada por Mullins et al. (1987) como uma das condições básicas para o aparecimento de horizontes com caráter hardsetting. Segundo o mesmo autor, a resistência do material fino (resultante das finas pontes entre as partículas) e o potencial mátrico do solo teriam um efeito direto na resistência daqueles horizontes, definindo esse comportamento.

Na Figura 1, observa-se o incremento dos teores de argila natural (ou dispersa em água) no horizonte com maior coesão (AB1). Essa maior proporção de argila mobilizada durante o umedecimento do solo no horizonte coeso (AB1) pode ser suficiente para manter as pontes interpartículas ou interagregados, determinando o maior grau de resistência desse horizonte, quando comparado com o horizonte não coeso (A1). Sinclair (1985), citado por Mullins et al. (1987) encontrou uma relação linear significativa entre o conteúdo de argila dispersa em água e resistência tênsil em vários solos hardsetting.

A distribuição dos teores de matéria orgânica pode ser visualizada na Tabela 3. Nota-se que, apenas no horizonte A1, os teores foram superiores a $2 \%$, provavelmente mantidos pela cobertura florestal presente na área. Nos demais horizontes, os níveis de matéria orgânica foram inferiores e atenderam à exigência de teores menores que $2 \%$ estabelecida para o comportamento hardsetting (Mullins, 1997). 


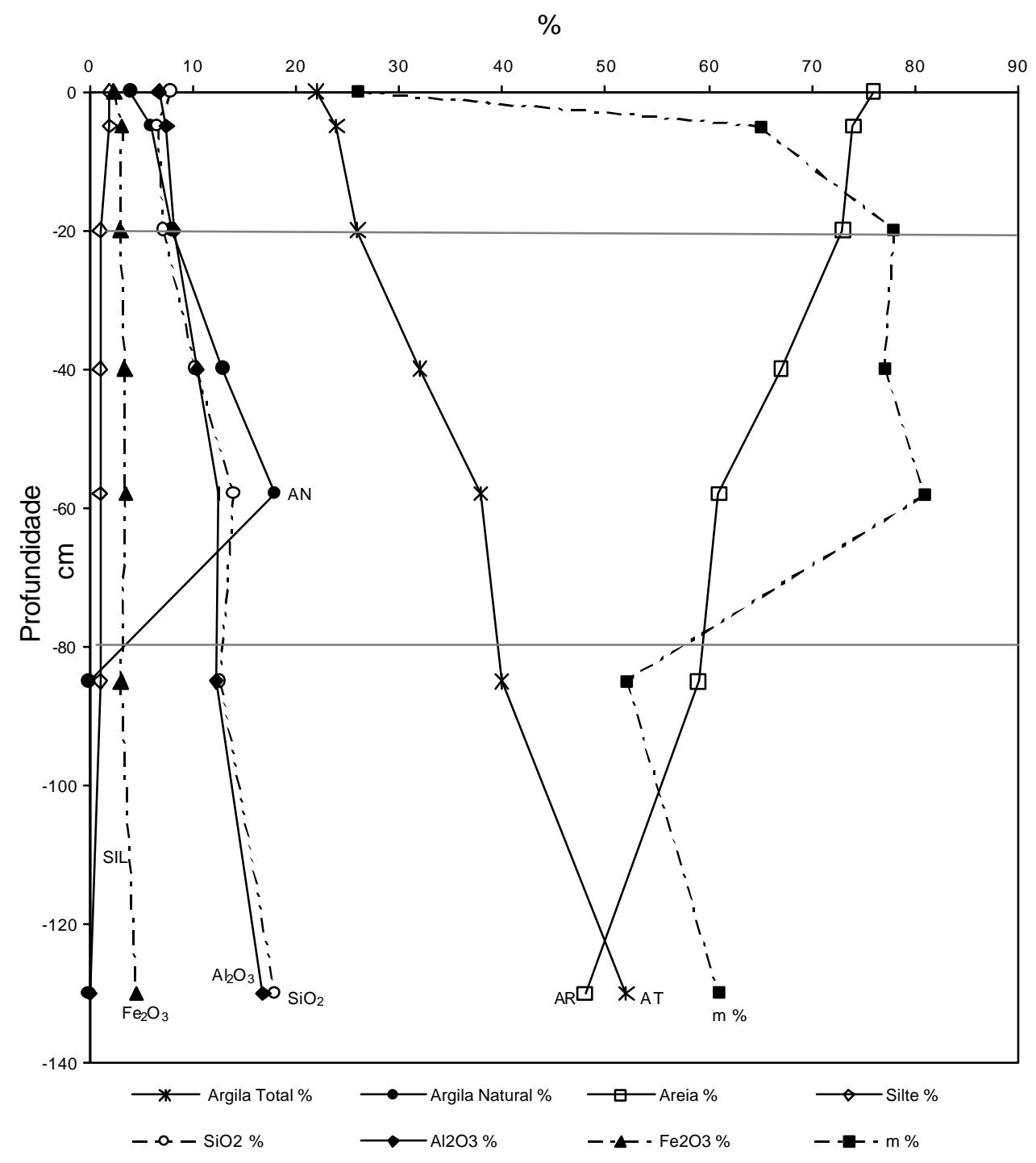

Figura 1 - Distribuição em profundidade dos percentuais das frações granulométricas, argila natural, óxidos do ataque sulfúrico e saturação por alumínio em Latossolo Amarelo Coeso. 
Tabela 3. Propriedades químicas do Latossolo Amarelo Coeso argissólico.

\begin{tabular}{ccccccccccc}
\hline \multicolumn{2}{c}{ Horizonte } & \multicolumn{2}{c}{$\mathrm{pH}$} & & $\mathrm{M} . \mathrm{O}$ & $\mathrm{P}$ & $\mathrm{SB}$ & $\mathrm{T}$ & $\mathrm{V}$ & $\mathrm{m}$ \\
Símb. & $\begin{array}{c}\text { Prof. } \\
\mathrm{cm}\end{array}$ & $\mathrm{H} 2 \mathrm{O}$ & $\mathrm{KCl}$ & $\mathrm{CaCl}_{2}$ & $\mathrm{~g} \mathrm{~kg}^{-1}$ & $\mathrm{mg} \mathrm{kg}^{-1}$ & $-\mathrm{mmolc} \mathrm{kg}^{-1}-$------ $^{2}$ & ----- \\
\hline A1 & $0-7$ & 4,5 & 3,9 & 4,1 & 29 & 7 & 20,0 & 65,0 & 31 & 26 \\
$\mathrm{~A} 2$ & $7-21$ & 4,1 & 3,7 & 3,7 & 19 & 6 & 5,3 & 45,3 & 12 & 65 \\
$\mathrm{AB} 1$ & $21-38$ & 4,0 & 3,6 & 3,6 & 12 & 4 & 2,9 & 31,9 & 9 & 78 \\
$\mathrm{AB} 2$ & $38-56$ & 3,8 & 3,5 & 3,5 & 9 & 2 & 3,2 & 36,2 & 9 & 77 \\
BA & $56-85$ & 3,7 & 3,4 & 3,3 & 12 & 2 & 3,5 & 42,5 & 8 & 81 \\
Bw1 & $85-130$ & 3,7 & 3,7 & 3,6 & 5 & 3 & 12,0 & 38,0 & 32 & 52 \\
Bw2 & $130-+$ & 3,8 & 3,6 & 3,4 & 8 & 2 & 7,0 & 33,0 & 21 & 61 \\
\hline
\end{tabular}

Analisando os teores de óxidos do ataque sulfúrico, observa-se a reduzida quantidade de óxidos de ferro decorrente do material parental, originalmente pobre nesses elementos (Ribeiro, 1998). Um pequeno incremento somente foi observado à medida que a profundidade aumentava e os teores de argila também eram incrementados (Tabela 4 e Figura 1).

Percebeu-se um aumento significativo nos teores de óxidos de alumínio e de silício, provavelmente em função do incremento de argila, bem como um incremento pronunciado na zona de maior coesão (Figura 1). Chartres et al. (1990) já haviam chamado a atenção para agentes cimentantes temporários como sílica amorfa e aluminossilicatos que, em conjunção com os mecanismos sugeridos por Mullins et al. (1987), contribuiriam para o desenvolvimento da resistência durante o secamento dos horizontes hardsetting. Ribeiro (1998) comprovou a presença de sílica amorfa em poros e canais de materiais de solos com caráter coeso da Formação Barreiras, demonstrando mais uma vez a similitude entre os dois atributos discutidos. 
Tabela 4. Teores em óxidos do ataque sulfúrico em Latossolo Amarelo Coeso argissólico.

\begin{tabular}{cccccc}
\hline \multicolumn{2}{c}{ Horizontes } & $\mathrm{SiO}_{2}$ & $\mathrm{Al}_{2} \mathrm{O}_{3}$ & $\mathrm{Fe}_{2} \mathrm{O}_{3}$ & $\mathrm{Ki}$ \\
Símb. & $\begin{array}{c}\text { Prof. } \\
\mathrm{cm}\end{array}$ & - ------------- $\%$ & & \\
\hline $\mathrm{A} 1$ & $0-7$ & 7,90 & 6,73 & 2,40 & 2,00 \\
$\mathrm{~A} 2$ & $7-21$ & 6,60 & 7,50 & 3,18 & 1,50 \\
$\mathrm{AB} 1$ & $21-38$ & 7,20 & 8,21 & 3,00 & 1,49 \\
$\mathrm{AB} 2$ & $38-56$ & 10,30 & 10,50 & 3,40 & 1,67 \\
$\mathrm{BA}$ & $56-85$ & 14,00 & 12,49 & 3,50 & 1,91 \\
$\mathrm{Bw} 1$ & $85-130$ & 12,70 & 12,29 & 3,07 & 1,76 \\
$\mathrm{Bw} 2$ & $130-+$ & 18,00 & 16,83 & 4,54 & 1,82 \\
\hline
\end{tabular}

A resistência do solo à penetração $(\mathrm{RP})$ permitiu diferenciar os distintos graus de coesão observados entre os dois horizontes analisados no perfil (não-coeso e coeso). A possibilidade de diferenciar os horizontes depende da umidade do solo. Quando o solo estava úmido, não houve diferença significativa entre as médias de resistência dos horizontes não-coeso (A1) e coeso (AB1); já com o solo mais seco, as diferenças foram altamente significativas. Na Figura 2 são apresentados os valores de $t$ quando da comparação das médias dos valores de resistência à penetração (horizonte coeso menos não-coeso), sob condições de solo úmido e seco. 


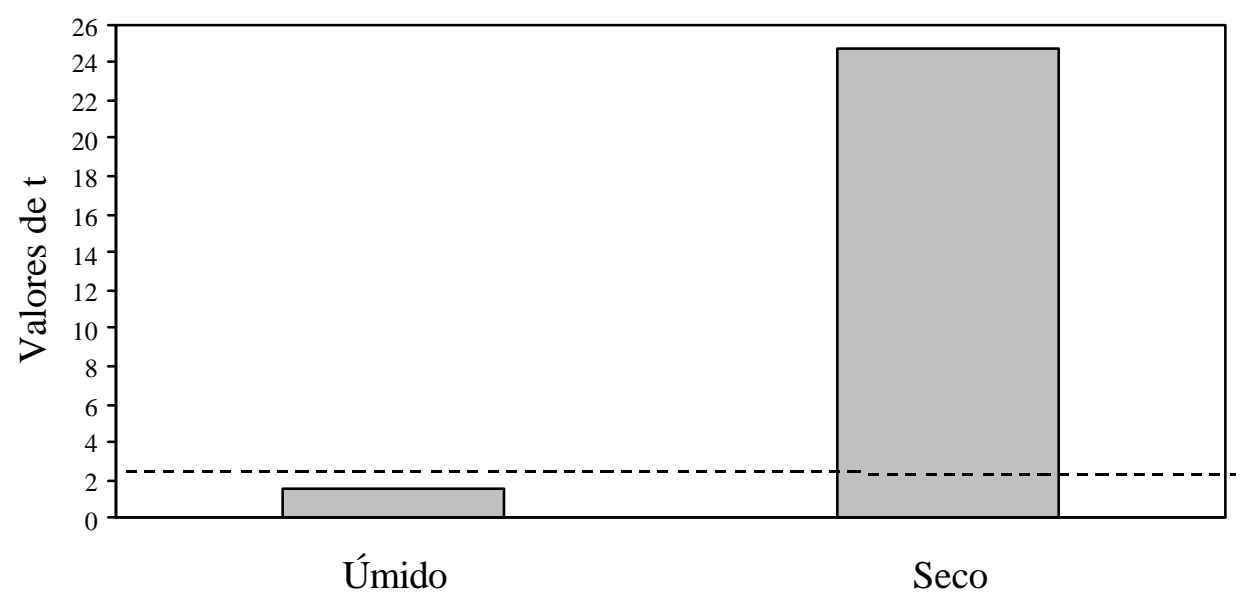

Figura 2 - Valores de $t$ da comparação das médias dos valores de resistência à penetração (horizonte coeso menos não-coeso), em dois níveis de umidade. A linha tracejada representa o valor de $t$ tabelado $(\mathrm{p}=5 \%)$. Valores acima da linha tracejada indicam diferença significativa a $5 \%$.

Com o solo úmido, o $\Delta \mathrm{RP}=0,22 \mathrm{MPa}(\mathrm{RP}=0,98 \mathrm{MPa}$ no coeso; 0,76 no nãocoeso). Sob condições de baixa umidade, o $\Delta \mathrm{RP}=11,32 \mathrm{MPa}(\mathrm{RP}=12,76 \mathrm{MPa}$ no coeso; 1,44 MPa no não coeso). Os valores de RP atingidos pelos horizontes coesos são considerados altamente restritivos ao crescimento radicular.

A relação funcional entre a RP e a $U$ para os dois horizontes estudados é apresentada na Figura 3. Nos dois horizontes, a RP aumentou com a redução da umidade do solo. Entretanto, o efeito da redução da umidade no aumento da RP foi drasticamente maior no horizonte coeso. $\mathrm{O} \delta \mathrm{RP} / \delta \mathrm{U}$ (coeficiente $b$ da equação 1 ), foi significativamente maior no horizonte coeso $(\mathrm{p}<0,001)$. 


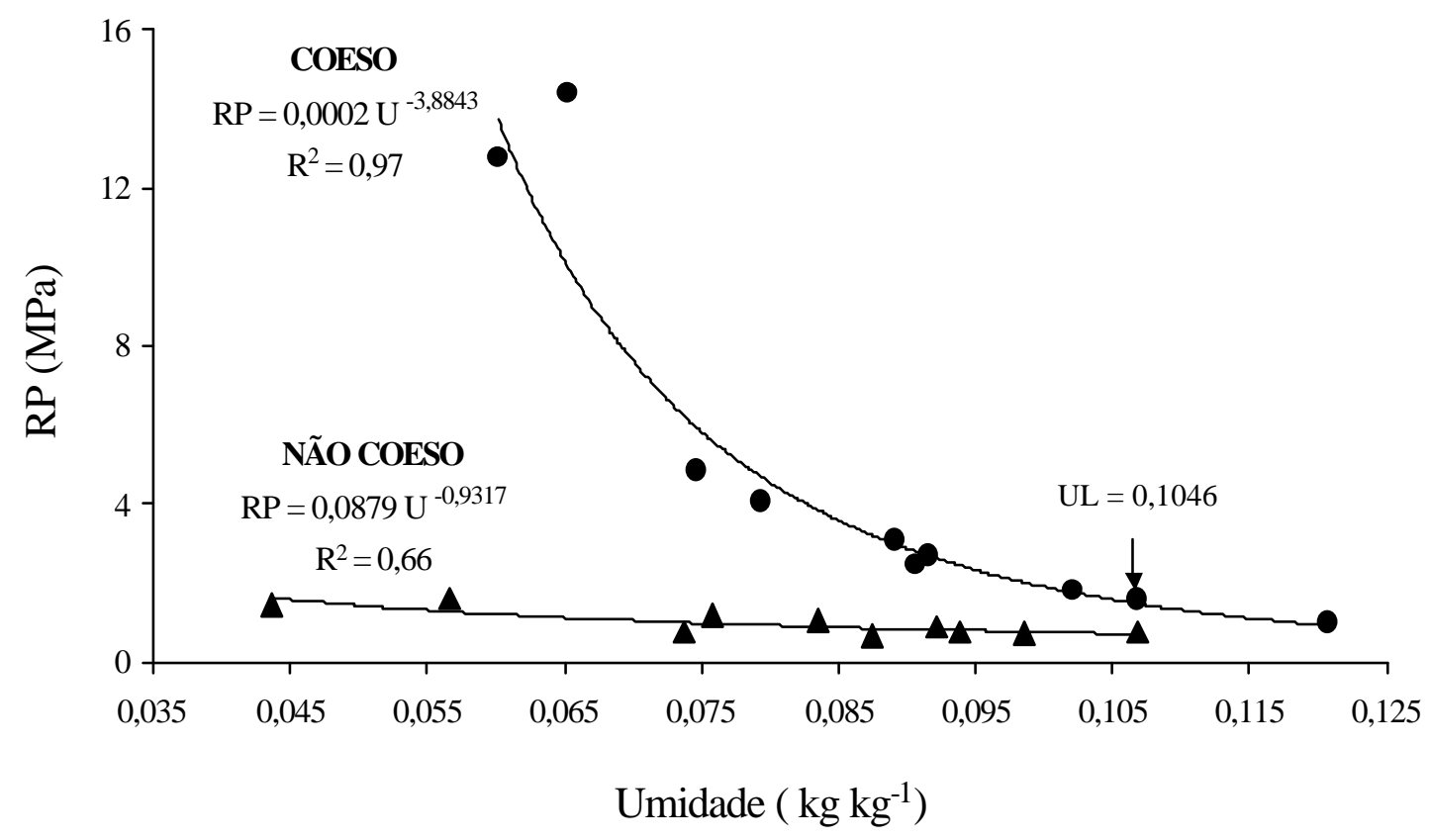

Figura 3 - Curvas de resistência à penetração dos horizontes A1 (não-coeso) e AB1 (coeso). As curvas são estatisticamente diferentes (5\%) em umidades inferiores à umidade limite (UL).

A análise do intervalo de confiança das curvas ajustadas indicou que as linhas de resistência são estatisticamente diferentes na quase totalidade da amplitude de variação da umidade gravimétrica. As curvas não diferem estatisticamente para $\mathrm{U} \geq 0,1046$ (kg $\mathrm{kg}^{-1}$ ), que corresponde a valores próximos da capacidade de campo do solo estudado. Esse comportamento também foi observado por Mullins et al. (1987), quando compararam solos hardsetting com solos não hardsetting do Reino Unido. 


\subsection{Conclusões}

Os resultados obtidos, tanto pela análise morfológica quanto pelas curvas de resistência do solo à penetração, demonstraram que as propriedades físicas e morfológicas analisadas são similares entre os horizontes coesos e os horizontes hardsetting.

Pesquisas desenvolvidas com o objetivo de estudar os horizontes coesos deveriam considerar a literatura disponível sobre horizontes hardsetting como fonte imprescindível de consulta. 


\section{Contribuição do adensamento natural das partículas do solo na ocorrência do caráter hardsetting}

\section{Resumo}

Muitos solos das regiões tropicais apresentam seções adensadas, geneticamente herdadas, que são denominadas hardsetting. A ocorrência de seções hardsetting é atribuída a certas propriedades físicas, químicas e mineralógicas. Formulou-se a hipótese de que o adensamento natural contribui significativamente com a ocorrência do caráter hardsetting em solos do Brasil. O objetivo do presente estudo foi determinar o efeito do adensamento natural na ocorrência de horizontes com caráter hardsetting em um Latossolo Amarelo Coeso argissólico. Esse efeito foi analisado: a) em lâminas delgadas e microtorrões, com base na análise das feições micropedológicas; b) em torrões, por meio de medidas de resistência tênsil; e c) em amostras indeformadas, pelo estudo da relação entre resistência do solo à penetração e estresse efetivo. A análise das seções delgadas e microtorrões revelou um empacotamento das partículas mais denso no horizonte hardsetting. A resistência tênsil dos torrões foi significativamente superior no horizonte hardsetting, provavelmente devido ao maior empacotamento das partículas. Para uma determinada variação de estresse efetivo $\left(\sigma^{\prime}\right)$, o incremento na resistência do solo à penetração $(S S)$ foi maior para o horizonte hardsetting, que também apresentou densidade do solo mais elevada. O adensamento natural do solo foi o principal fator que, direta ou indiretamente, influenciou as propriedades físicas e morfológicas analisadas e foi responsável pelas diferenças observadas entre horizontes hardsetting e não hardsetting, confirmando a hipótese testada. 


\section{Summary: "Contribution of natural soil compaction on hardsetting behaviour"}

Many soils in tropical countries present genetically inherited compacted layers, which are commonly referred to as hardsetting. The occurrence of hardsetting is attributable to certain soil physical, chemical and mineralogical properties. We hypothesized that natural soil compaction contributes significantly to the occurrence of a hardsetting behaviour in soils from Brazil. The aim of study was to determine the effect of natural soil compaction on the occurrence of hardsetting horizons of a clayey Yellow Cohesive Latosol. This effect was analyzed: a) in thin sections and microclods, by determining micropedological features, b) in soil clods, by measuring tensile strength, c) in undisturbed samples, by determining the relationship between soil strength and effective stress. The analysis of thin sections and microclods revealed a denser particle packing for the hardsetting horizon. Tensile strength of the clods was significantly higher for the hardsetting horizon, probably due to higher packing of particles. For the variation in effective stress $\left(\sigma^{\prime}\right)$, the increment in soil strength $(S S)$ was higher for the hardsetting horizon which also had a higher $\mathrm{B}$. The natural soil compaction was the main factor that, directly or indirectly, influenced the physical and morphological properties analyzed and was responsible for the differences observed between nonhardsetting and hardsetting horizons, confirming the tested hypothesis.

\subsection{Introdução}

Hardsetting é um comportamento de solo bastante comum e caracteriza solos que desenvolvem alta resistência mecânica quando secos, e que perdem grande parte dessa resistência, quando úmidos (Mullins et al., 1987; Mullins et al., 1990). A ocorrência do comportamento hardsetting é atribuída a determinadas propriedades físicas, químicas e mineralógicas dos solos (Norwish \& Pickering, 1983; Mullins et al., 1990; Young, 1992). Em alguns solos australianos, Chartres et al. (1990), Chartres \& Norton (1994) e Franzmeier et al. (1996) demonstraram que esse comportamento era causado por cimentação temporária das partículas por meio de agentes químicos como sílica amorfa, 
possivelmente combinada a óxidos de ferro. Por outro lado, Breuer \& Schwertmann (1999) observaram que o efeito hardsetting se mantinha mesmo depois da eliminação da sílica amorfa do solo.

A contribuição de processos físicos ao fenômeno hardsetting foi enfatizado por Mullins et al., 1992a, Mullins et al, 1992b e Weaich et al., 1992. Quando não ocorria agregação das partículas do solo (em função da ausência ou teores reduzidos de óxidos de ferro e matéria orgânica), as partículas finas (argila e silte), que são móveis, eram rearranjadas, formando conexões estruturais (pontes) entre as partículas de areia, no momento em que o solo secava (Mullins et al., 1987; Lamotte et al., 1997a, b). A resistência dessas conexões e a tensão mátrica aumentavam com a diminuição do conteúdo de água. A ligação entre as partículas e a resistência dos solos secos foram, então, atribuídas ao efeito do potencial mátrico (estresse efetivo) sobre as pontes interpartículas e interagregados (Mullins \& Panayiotopoulos, 1984; Mullins, et al., 1987; Mullins, et al., 1990). Posteriormente, Franzmeier et al. (1996) também reconheceram que a ocorrência desse comportamento não era devida somente à ação de agentes químicos cimentantes temporários, mas ao efeito do potencial mátrico, o qual incrementava a resistência do solo durante o secamento.

Muitos autores enfatizaram o papel do estresse efetivo na geração de níveis elevados de resistência do solo, particularmente em solos com comportamento hardsetting (Mullins \& Panayiotopoulos, 1984; Mullins, 1989; Ley et al., 1993). Vepraskas (1984) demonstrou uma forte correlação entre resistência do solo e estresse efetivo, mas o efeito do estresse efetivo sobre a resistência era, na verdade, influenciado pela densidade do solo $\left(\mathrm{D}_{\mathrm{s}}\right)$ e tipo de solo.

A ocorrência de solos hardsetting no Brasil foi indicada por Mullins et al. (1990). Recentemente, Giarola et al. (2001) identificou, na região nordeste, solo com horizonte hardsetting, por meio da quantificação da relação entre resistência à penetração e conteúdo de água, no campo. O mesmo horizonte foi descrito, regionalmente, como “coeso", fato que permitiu considerar a ambos similares neste trabalho. O número de estudos a respeito da influência de processos físicos na ocorrência de solos hardsetting ainda é bastante reduzido. Diante disto, para formulourse para o estudo a hipótese de que 
o adensamento natural das partículas contribui significativamente na ocorrência do comportamento hardsetting (leia-se aqui, também, "coeso") em um solo do Brasil. O objetivo deste trabalho foi determinar o efeito do adensamento natural na ocorrência do comportamento hardsetting em um Latossolo Amarelo Coeso argissólico, utilizando atributos físicos e morfológicos.

\subsection{Material e Métodos}

\subsection{1 Área de estudo e solo selecionado}

O estudo foi realizado na região nordeste do Brasil, no município de Cruz das Almas, Bahia, situado a $12^{\circ} 40^{\prime} 19^{\prime \prime}$ S e 3906'22” W, e a $220 \mathrm{~m}$ de altitude. O clima da região varia de seco a subúmido (EMBRAPA, 1981), com umidade relativa do ar de $80 \%$, temperatura média anual de $24^{\circ} \mathrm{C}$ e precipitação média anual de $1.200 \mathrm{~mm}$.

O solo utilizado foi coletado sob floresta secundária preservada e descrito por Giarola et al. (2001) como um solo hardsetting oriundo dos sedimentos argilo-arenosos do Grupo Barreiras (Jacomine, 1996). O solo é bastante intemperizado (caulinítico), com estrutura pouco expressa, baixo teor de matéria orgânica e baixa capacidade de troca de cátions (CTC) (Tabela 1).

Quando seco, o horizonte hardsetting apresenta consistência dura a muito dura, mas se abranda rapidamente quando umedecido. $O$ perfil foi classificado como Latossolo Amarelo Coeso argissólico (EMBRAPA, 1999) e typical Kanhaplustults (USA, 1998). Os horizontes A1 (não-hardsetting) e AB1 (hardsetting), classificados como franco-argilo-arenoso (USDA) / média (FAO) foram utilizados para os testes de laboratório. 
Tabela 1. Densidade do solo $\left(\mathrm{D}_{\mathrm{s}}\right)$, conteúdo de areia, silte, argila, teor de matéria orgânica (M.O.), pH, e capacidade de troca de cátions (CTC) dos horizontes selecionados.

\begin{tabular}{|c|c|c|c|c|c|c|c|c|c|c|c|c|c|}
\hline \multicolumn{2}{|c|}{ Horizonte } & \multirow[t]{2}{*}{$\mathrm{D}_{\mathrm{s}}$} & \multirow{2}{*}{$\begin{array}{c}\text { Argila } \\
<0.002\end{array}$} & \multicolumn{5}{|c|}{ Areia } & \multirow{2}{*}{$\begin{array}{l}\text { Areia } \\
\text { Total }\end{array}$} & \multirow{2}{*}{$\begin{array}{l}\text { Silte } \\
\\
0.05- \\
0.002\end{array}$} & \multirow{2}{*}{ M.O. } & \multirow{2}{*}{$\begin{array}{c}\mathrm{pH} \\
\mathrm{CaCl}_{2}\end{array}$} & \multirow[t]{2}{*}{ СТC } \\
\hline Símb. & Prof. & & & $2.00-1.00$ & $1.00-0.50$ & $0.50-0.25$ & $0.25-0.10$ & $0.10-0.05$ & & & & & \\
\hline & $\mathrm{cm}$ & $\mathrm{Mg} \mathrm{m}^{-3}$ & - & 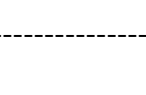 & -_-_- & 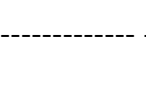 & $\mathrm{g} \mathrm{kg}^{-1}$ & 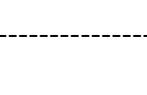 & 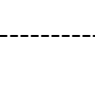 & - & -..- & & $\mathrm{mmol}_{\mathrm{cm}} \mathrm{kg}^{-1}$ \\
\hline A 1 & $0-7$ & 1,39 & 220 & 20 & 220 & 290 & 190 & 40 & 760 & 20 & 29 & 4,1 & 65,0 \\
\hline $\mathrm{AB} 1$ & $21-38$ & 1,57 & 260 & 30 & 190 & 230 & 230 & 50 & 730 & 10 & 12 & 3,6 & 31,9 \\
\hline
\end{tabular}


O efeito do adensamento natural na ocorrência do comportamento hardsetting foi analisado: a) em lâminas delgadas e microtorrões, pela determinação das feições micropedológicas, b) em torrões do solo, por meio de medidas de resistência tênsil e, c) em amostras indeformadas, por meio da determinação da relação entre resistência do solo à penetração e estresse efetivo.

\subsubsection{Lâminas delgadas e microtorrões}

A análise de lâminas delgadas (micromorfológica) foi realizada em lâminas finas de vidro preparadas a partir de blocos indeformados dos horizontes do solo. Para a descrição das lâminas fez-se uso de um microscópio petrográfico Axioplan Zeiss e das terminologias sugeridas por Brewer (1976), traduzidas por Lima et al. (1985) e Brewer \& Sleeman (1988). As proporções de grãos e plasma foram obtidas em analisador de imagem, utilizando-se o programa KS-400. As quantidades de poros foram obtidas por diferença.

Cinco microtorrões, com estrutura indeformada e medindo cerca de $120 \mathrm{~mm}^{3}$, foram retirados de cada horizonte estudado e analisados em microscópio eletrônico de varredura (MEV) marca JEOL, modelo 5600 LV. As feições micropedológicas foram determinadas nos microtorrões, previamente recobertos por uma película de ouro de cerca de 6 A de espessura.

\subsubsection{Torrões do solo}

Foram utilizados quarenta torrões $(13-19 \mathrm{~mm})$ de cada horizonte estudado: nãohardsetting (A1) e hardsetting (AB1). Os torrões foram obtidos a partir de um bloco indeformado de cada horizonte, que foi seco ao ar e manualmente desagregado. A resistência tênsil foi medida utilizando-se equipamento e procedimento descritos por Imhoff et al. (2002). A resistência tênsil foi calculada segundo Dexter \& Kroesbergen (1985), e o diâmetro efetivo de cada torrão foi calculado como sugerido por Watts \& Dexter (1998). 


\subsubsection{Amostras indeformadas}

Quarenta e três $(\mathrm{n}=43)$ amostras indeformadas $\left(100 \mathrm{~cm}^{3}\right)$ foram coletadas de cada horizonte (hardsetting e não-hardsetting). As amostras foram saturadas com água e então submetidas a diferentes potenciais mátricos $(\psi)$ utilizando mesa de tensão e câmaras de pressão segundo Klute (1986). Os $\psi$ aplicados nas amostras foram: 0, -2, -4, $-5,-6,-10,-20,-30,-50,-100$, e $-1500 \mathrm{kPa}$. Depois de alcançado o equilíbrio, a resistência do solo foi medida com o penetrômetro descrito por Imhoff et al. (2000). Em seguida as amostras foram secas a $105^{\circ} \mathrm{C}$ for $24 \mathrm{~h}$ e a densidade do solo $\left(\mathrm{D}_{\mathrm{s}}\right)$ e o conteúdo de água volumétrico $\left(\theta_{\mathrm{cc}}\right)$ foram determinados de acordo com Blake \& Hartge (1986).

O estresse efetivo foi calculado utilizando-se a equação sugerida por Mullins \& Panayiotopoulos (1984) para solos não saturados:

$$
\sigma^{\prime}=S\left|\psi_{m}\right|
$$

onde: $\sigma$ ' é o estresse efetivo $(\mathrm{kPa}), S$ representa o grau de saturação (saturação relativa) determinado pela relação entre conteúdo de água a um dado potencial $\left(\theta_{\mathrm{cc}}, \mathrm{cm}^{3}\right.$ $\left.\mathrm{cm}^{-3}\right)$ e conteúdo de água na saturação $\left(\theta_{\mathrm{s}}, \mathrm{cm}^{3} \mathrm{~cm}^{-3}\right)$, e $\psi_{m}$ é o potencial mátrico aplicado $(\mathrm{kPa})$.

O seguinte modelo foi ajustado aos dados utilizando o software estatístico SAS (Statistical Analysis System Institute, 1991):

$$
S S=a+b \sigma
$$

onde: $S S$ é a resistência do solo à penetração em $\mathrm{kPa}, a$ e $b$ são coeficientes empíricos. Testou-se se $a$ e $b$ são dependentes do tipo de horizonte.

\subsubsection{Análise estatística}

A normalidade dos dados de $\mathrm{D}_{\mathrm{s}}$ e $Y$ foi testada utilizando-se a estatística de Shapiro-Wilk (Statistical Analysis System Institute, 1991), em que a hipótese de nulidade indica que os dados amostrais provêm de uma população com distribuição normal. A estatística de Shapiro-Wilk fornece um valor $\mathrm{W}$ com um valor $p$ 
correspondente. A hipótese de nulidade da normalidade é rejeitada somente quando o valor $p$ for menor do que 0,05 .

\subsection{Resultados e Discussão}

\subsubsection{Feições micromorfológicas}

A observação das lâminas delgadas (Figuras 1a e b) demonstrou pequena variação entre os horizontes não-hardsetting (A1) e hardsetting (AB1) em relação à proporção entre grãos, plasma e poros. Maiores diferenças foram observadas na porosidade total obtida por análise de imagem das fotografias das lâminas, as quais demonstraram uma redução na porosidade do não-hardsetting (38\%), comparada ao hardsetting (31\%). Os vazios (“cavidades") eram menores no horizonte mais adensado (Figuras 1a e b) e os valores de porosidade, similares àqueles calculados a partir da $D_{s}$ das amostras indeformadas, indicando o adensamento pedogenético do horizonte hardsetting. Os estudos micromorfológicos realizados por Mullins et al. (1990), Chartres

\& Norton (1994) e Silva et al. (1998) comprovaram o adensamento natural das partículas nos horizontes hardsetting de solos da Austrália e Brasil.

A análise de imagens demonstrou uma proporção similar da área superficial ocupada por grãos de esqueleto (fração areia) para os horizontes não-hardsetting e hardsetting (37 e 35\%, respectivamente), que consistiu, basicamente, de $100 \%$ de grãos quartzo, subangulares, subarredondados, arredondados e esféricos.

A proporção das frações areia grossa e fina em relação ao plasma foi intertextural para o não-hardsetting (Figura 1a) e porfirosquélica intertextural para o hardsetting (Figura 1b). 

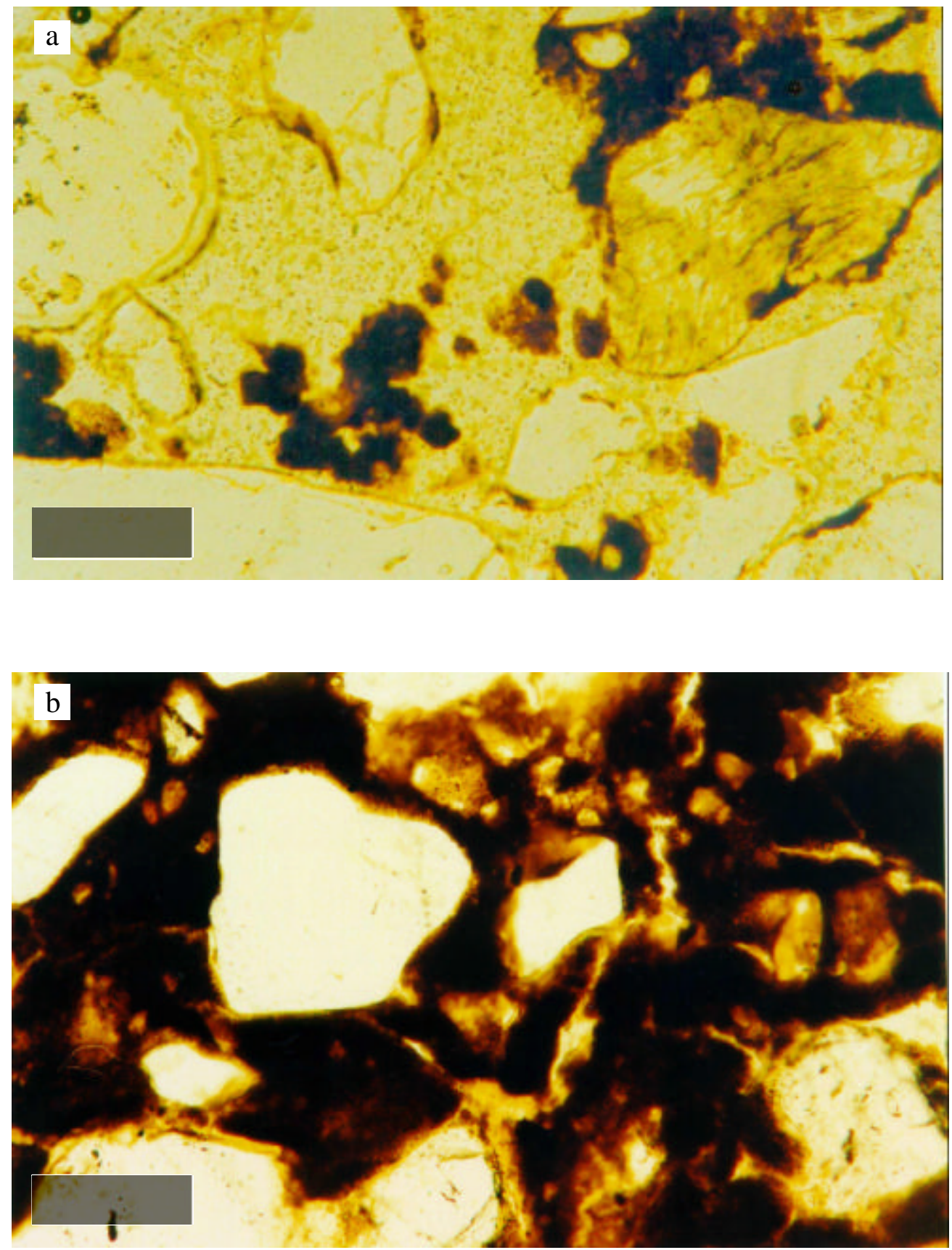

Figura1.Vista,emlâminasdelgadas,doarranjoestruturaldaspartículasdoshorizontes 
O horizonte franco-argilo-arenoso AB1 (consistência dura, quando seco) é composto por grãos de quartzo do tamanho areia, com uma contextura matricial sustentada por grãos e partículas de argila que unem os grãos de areia maiores. Esta geometria é utilizada com modelo para explicar a resistência do solo no trabalho de Mullins et al. (1987) e Lamotte et al. (1997a). A diferença no empacotamento das partículas entre os horizontes A1 e AB1 pode estar relacionada ao desenvolvimento de pontes de argila entre os grãos do esqueleto no horizonte hardsetting (Figura 1b), assim como ao maior empacotamento da fração areia (grãos do esqueleto).

A falta de estrutura macroscópica no perfil do solo e a forma contínua da fase sólida da matriz do solo do horizonte hardsetting (Figura 1b) confirmam o incremento do empacotamento das partículas que, por sua vez, pode explicar o considerável incremento na resistência desse horizonte.

A análise visual ao MEV revelou maior porosidade e menor empacotamento de partículas no horizonte não-hardsetting (Figuras $2 \mathrm{a}, \mathrm{b}$ ). 

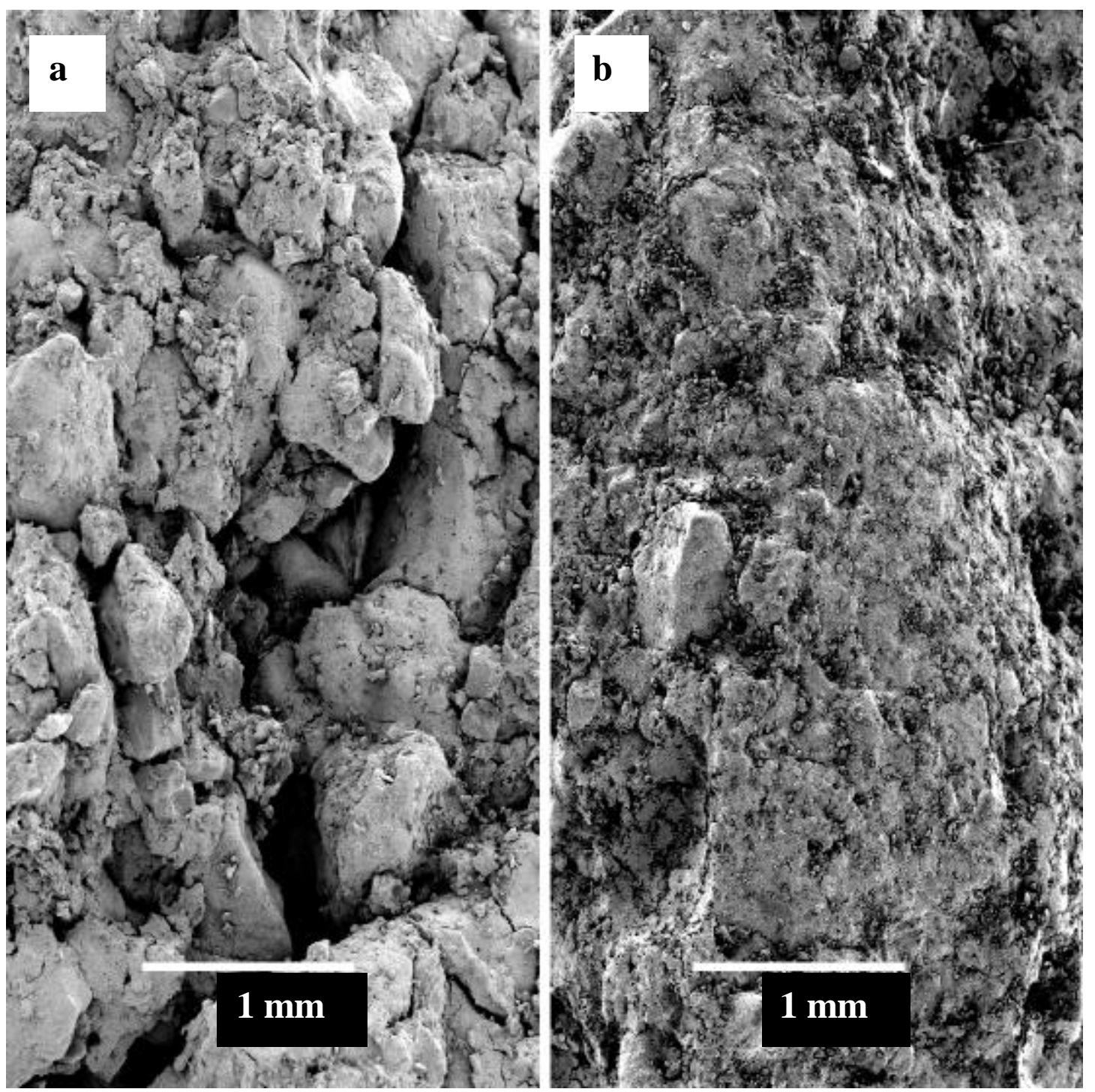

Figura 2 - Vista ao microscópio eletrônico de varredura do arranjo estrutural das partículas dos horizontes não-hardsetting ( a ) e hardsetting ( b ).

\subsubsection{Resistência tênsil}

Testes estatísticos ind icaram que a resistência tênsil, $Y$, dos torrões secos ao ar apresentou uma distribuição log-normal tanto para o horizonte não-hardsetting ( $\mathrm{W}=$ $0,9793, \mathrm{p}<\mathrm{W}=0,6651$ ) como para o hardsetting ( $\mathrm{W}=0,9572, \mathrm{p}<\mathrm{W}=0,1338$ ) (Figura 
3). Resultados similares de resistência tênsil foram encontrados por Skidmore \& Layton (1992) e Imhoff et al. (2002). Contrariamente, Dexter \& Watts (2000) indicaram que a resistência tênsil apresentava uma distribuição normal.

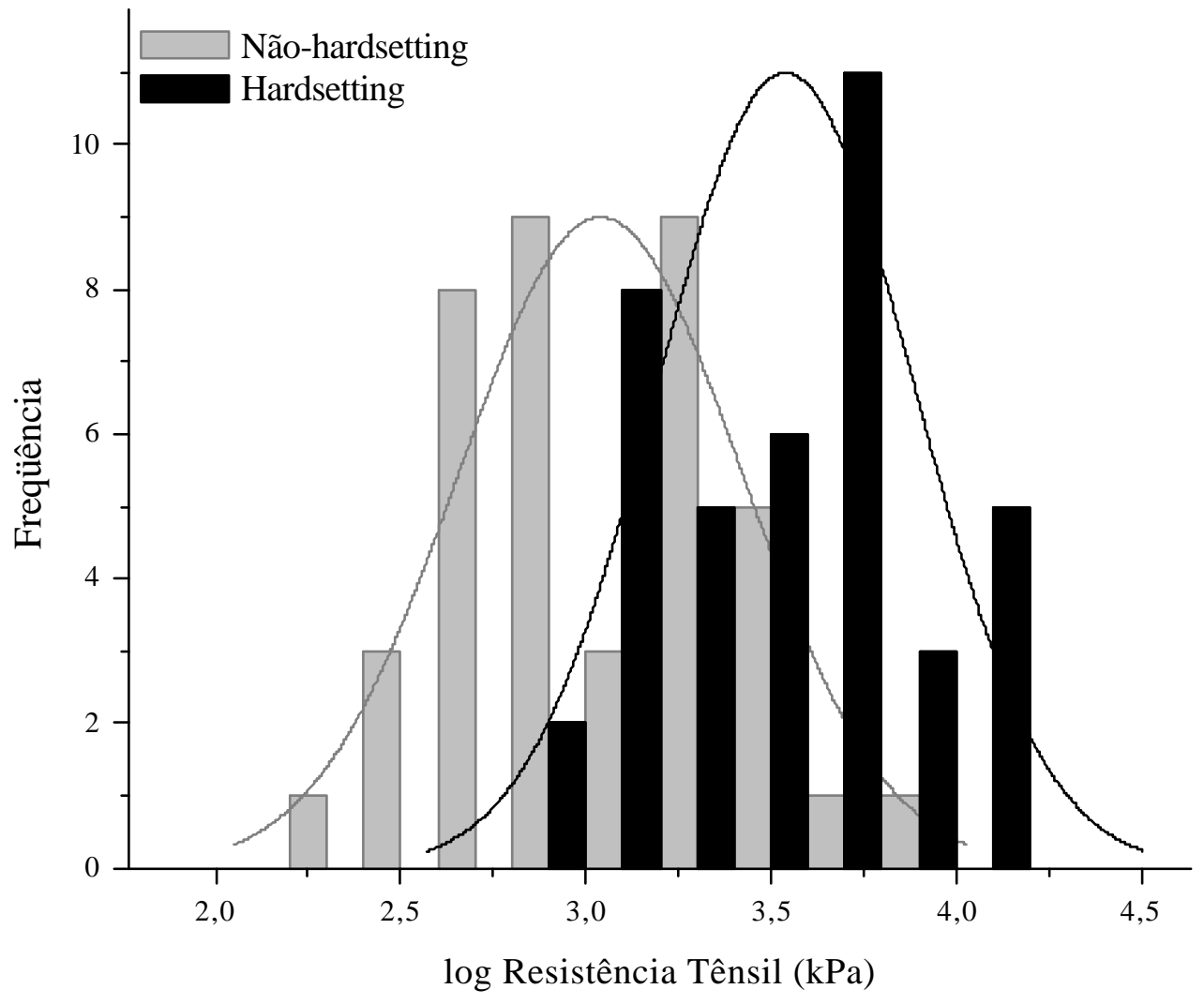

Figura 3 - Distribuição de freqüência da Resistência Tênsil ( $Y$ ) dos horizontes nãohardsetting (A1) e hardsetting (AB1).

Os torrões do horizonte A1 foram significativamente $(\mathrm{P}<0,0001)$ menos resistentes do que os do horizonte $\mathrm{AB} 1$, cujas médias aritméticas de resistência tênsil obtidas foram de $Y=22,47$ (A1) e 36,56 (AB1) kPa, respectivamente. A distribuição dos valores de $Y$ transformados (logaritmo na base $e$ ) apresentaram média \pm erro padrão de 
$3,039 \pm 0,061$ e 3,539 $\pm 0,055$, respectivamente. Estes valores são significativamente diferentes ao nível de $\mathrm{p}<0,001$, que sustenta as observações de campo de que os torrões do horizonte A1 apresentavam uma consistência de campo mais fraca do que o horizonte AB1. Os valores médios de $Y$ foram similares aos obtidos por Mullins et al. (1992), Weaich et al. (1992) e Gusli et al (1994) em solos hardsetting da Austrália.

A diferença em resistência tênsil $(\mathrm{A} 1<\mathrm{AB} 1)$ não teve relação com a textura do solo, pois os dois horizontes apresentavam conteúdo de argila similar, indicando que fatores outros seriam os determinantes dessa diferença. A umidade do solo é um dos

principais fatores que influenciam a $Y$ (Causarano, 1993; Perfect et al., 1995). Entretanto, para a faixa de conteúdo de água gravimétrica (seco ao ar) não houve relação significativa entre $Y$ e umidade do solo, isto é, $(\mathrm{P}<0,09)$ para A1 e $(\mathrm{P}<0,79)$ para o horizonte $\mathrm{AB} 1$.

A resistência tênsil é positivamente relacionada com o adensamento do solo (Smith et al., 1997). A maior resistência tênsil do horizonte hardsetting pode indicar a maior influência do empacotamento mais denso das partículas. Esta afirmação é sustentada pelos estudos conduzidos por Ley et al. (1989) e Young et al. (1991).

\subsubsection{Resistência do solo versus estresse efetivo}

A interação entre conteúdo de água e potencial mátrico influencia a resistência do solo, por regular o estresse efetivo (Ley et al., 1993), e este, por sua vez, é influenciado pela densidade do solo (Vepraskas, 1984; Smith et al., 1997). A relação entre resistência do solo à penetração e estresse efetivo $\left(\sigma^{\prime}\right)$ para os horizontes nãohardsetting e hardsetting é demonstrada na Figura 4, e foi adequadamente representada por uma função linear. Resultados similares foram obtidos por Mullins et al. (1992b), Weaich et al. (1992) e Ley et al. (1993) em solos hardsetting da Austrália e Nigéria, respectivamente. 


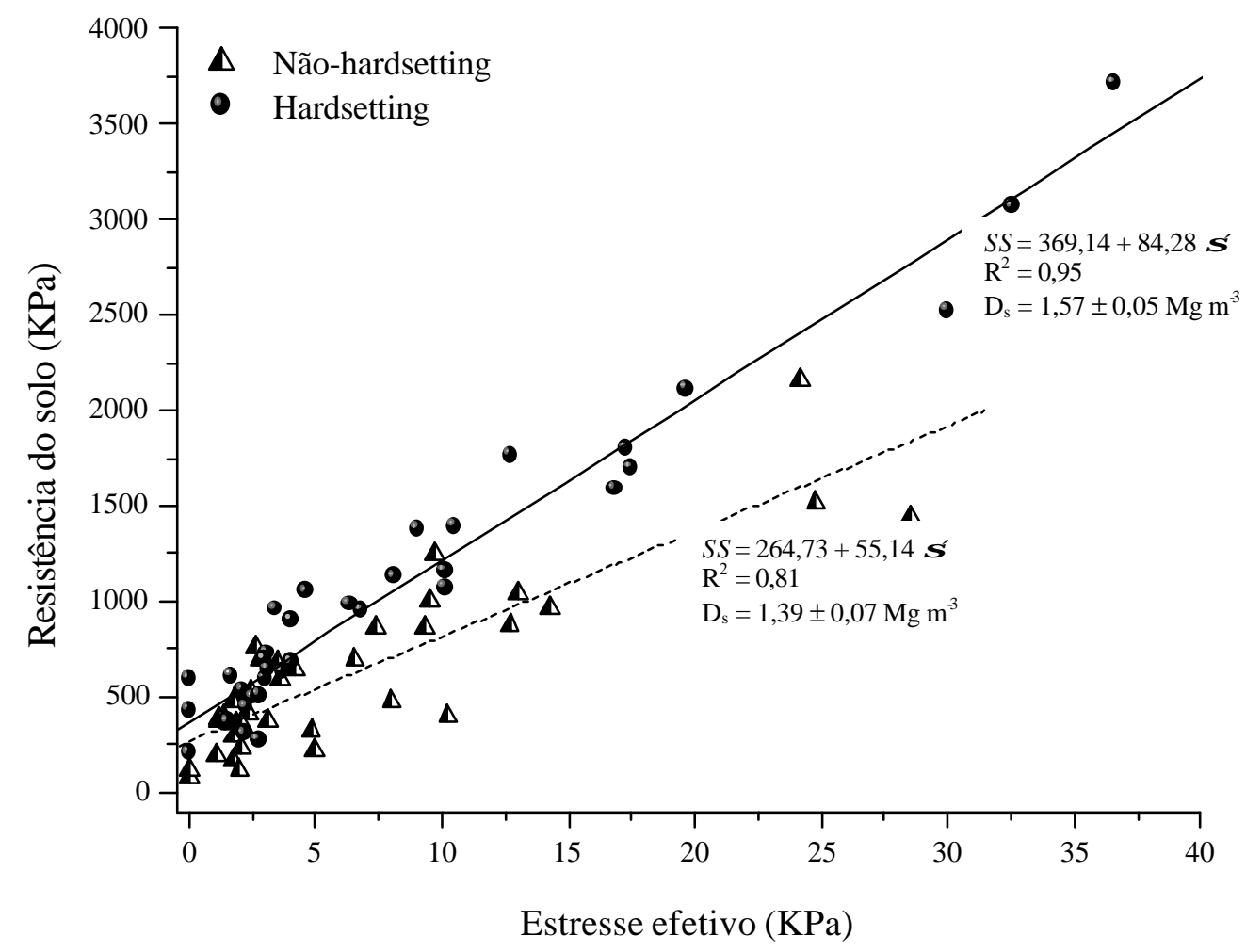

Figura 4 - Resistência do solo à penetração $(S S)$ versus estresse efetivo ( $\left.\sigma^{\prime}\right)$ para os horizontes não-hardsetting (A1) e hardsetting (AB1).

Para a variação de estresse efetivo $\left(\sigma^{\prime}\right)$ observada, o incremento da resistência foi maior para o horizonte hardsetting, que também apresentava maior $\mathrm{D}_{\mathrm{s}}$ (Figura 4). Esta mesma situação foi evidenciada por Vepraskas (1984) e Smith et al. (1997) em solos dos Estados Unidos e África do Sul, respectivamente. Quando a $\mathrm{D}_{\mathrm{s}}$ aumenta, o contato entre as partículas é incrementado, resultando em maior fricção interpartículas e, consequentemente, maior resistência do solo. Este fato sugere que as diferenças nas relações $S S-\sigma$ ' observadas entre os horizontes são, provavelmente, devido às diferenças de $\mathrm{D}_{\mathrm{s}}$ existentes entre os mesmos, sendo a $\mathrm{D}_{\mathrm{s}}$ maior no horizonte hardsetting. 
Vepraskas (1984) e Poch \& Verplancke (1997) indicaram que o coeficiente linear ( $a$ na Eq. 2) é relacionado à coesão gerada por agentes químicos cimentantes, enquanto que a inclinação ( $b$ na Eq. 2) depende do estresse efetivo $\left(\sigma^{\prime}\right)$ e da resistência friccional entre os grãos.

O coeficiente $a$ não diferiu significativamente entre os horizontes $(t=-1,69 ; \mathrm{P}<$ 0,095), indicando que os agentes químicos cimentantes não determinaram os incrementos de resistência do solo, concordando com o que foi verificado por Weaich et al. (1992) e McKyes et al. (1994) em solos hardsetting da Austrália e Zimbabwe, respectivamente. Ley et al. (1989) já haviam demonstrado que seria pouco provável que acréscimos pronunciados em RP ocorressem para pequenas variações no conteúdo de umidade, em função de um acréscimo súbito em elementos químicos cimentantes.

$\mathrm{O}$ parâmetro $b$ diferiu significativamente entre os horizontes $(t=-4,78 ; \mathrm{P}<$ 0,0001), indicando que as diferenças de RP determinadas foram devidas, principalmente, ao incremento do estresse efetivo e da resistência friccional entre os grãos. Os modelos (Figura 4) demonstraram que o estresse efetivo explicou 95\% e $81 \%$ da variação da $S S$ nos horizontes hardsetting e não-hardsetting, respectivamente. Uma forte correlação entre SS e estresse efetivo também foi obtida por Vepraskas (1984) para solos dos Estados Unidos. Entretanto, este último autor observou que, além do estresse efetivo, a resistência do solo também havia sido influenciada pela $D_{s}$ e pelas características das partículas do solo. Em solos com horizontes ricos em gesso, Poch \& Verplancke (1997) também obtiveram relações similares entre resistência do solo e $\sigma$, e indicaram a $D_{s}$ como o principal agente controlador do estresse efetivo que, por sua vez, influenciou a resistência do solo à penetração.

A distribuição de freqüência da $D_{s}$ é apresentada na Figura 5, e indica uma distribuição normal tanto para o horizontes não-hardsetting $(\mathrm{W}=0,966, \mathrm{p}<\mathrm{W}=0,274)$ como para o hardsetting $(\mathrm{W}=0,978, \mathrm{p}<\mathrm{W}=0,614)$. $\mathrm{A}_{\mathrm{s}}$ foi relatada como uma variável com distribuição normal (Nielsen et al. 1973; Silva et al. 1997). 


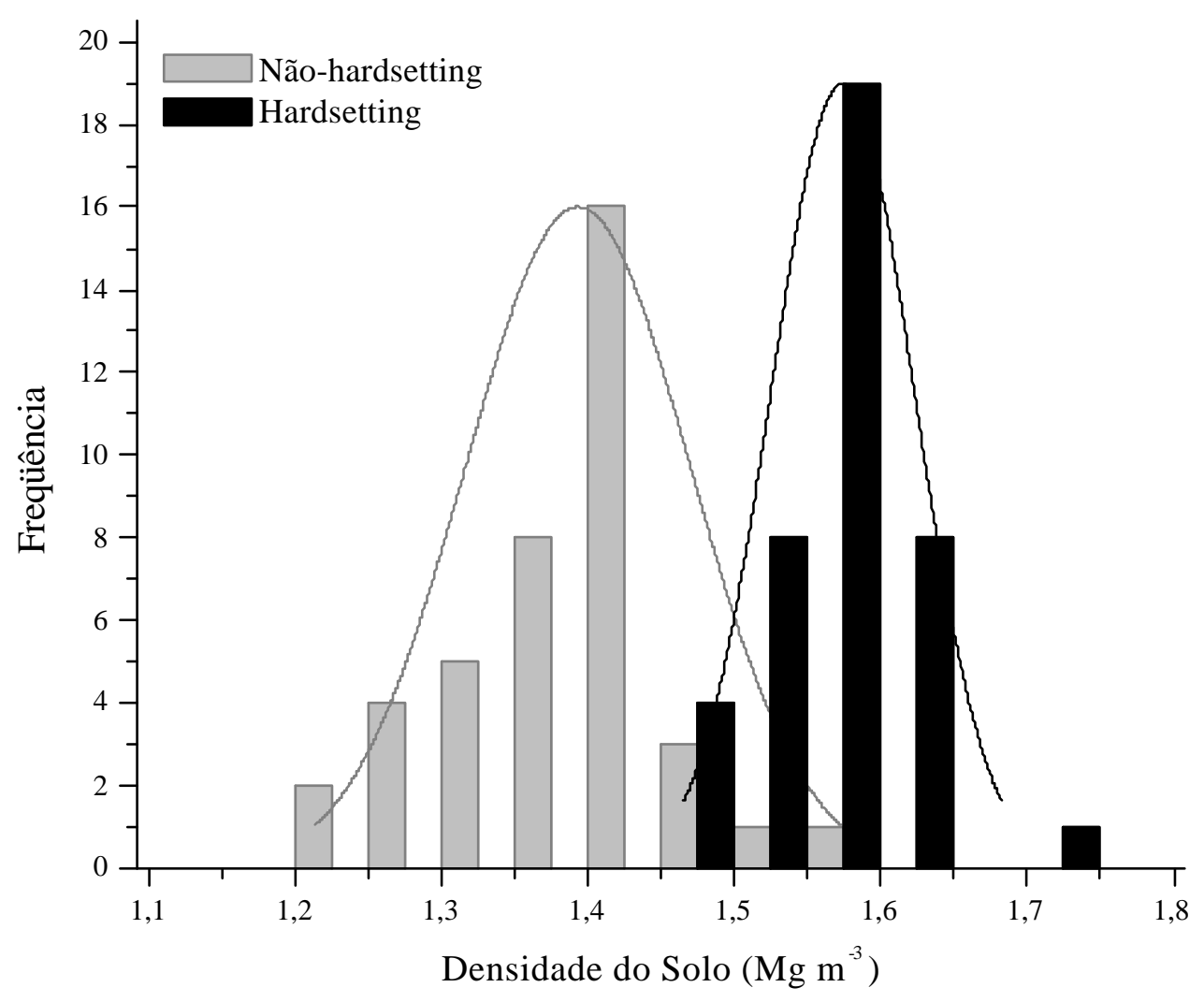

Figura 5 - Distribuição de frequiência da $D_{s}$ para os horizontes não-hardsetting (A1) e hardsetting ( $\mathrm{AB} 1)$.

$\mathrm{A} \mathrm{D}_{\mathrm{s}}$ foi significativamente maior $(\mathrm{P}<0,0001)$ no horizonte hardsetting, com média \pm erro padrão de $1,57 \pm 0,01 \mathrm{Mg} \mathrm{m}^{-3}$, do que no não-hardsetting $(1,39 \pm 0,01 \mathrm{Mg}$ $\mathrm{m}^{-3}$ ) (Figura 5). Esta diferença sugere que a $D_{s}$ foi o principal fator que influenciou o estresse efetivo, e que determinou as diferenças de resistência do solo entre os dois horizontes, levando à ocorrência do comportamento hardsetting no horizonte AB1. 


\subsection{Conclusões}

O adensamento natural do solo, determinado por meio das feições micromorfológicas, resistência tênsil, resistência do solo à penetração e densidade do solo, foi o principal fator que, direta ou indiretamente, influenciou as propriedades físicas e micromorfológicas analisadas e foi o responsável pelas diferenças observadas entre os horizontes não-hardsetting e hardsetting, comprovando a hipótese testada. 


\section{CONCLUSÕES GERAIS}

Os conceitos, ocorrência, características físicas, químicas e mineralógicas descritos para o atributos hardsetting e coeso, apresentam uma série de coincidências. Este fato indica que pode se tratar de um mesmo tipo de comportamento de solo, ao qual foram dadas denominações distintas.

No Brasil, as pesquisas realizadas sobre o caráter coeso dos solos ainda são incipientes. Apesar de os estudos desta natureza terem sido iniciados em 1968, seguiu-se um período de 1970 a 1980 em que poucos trabalhos foram produzidos. Este fato não permitiu que os conceitos e critérios para a distinção do caráter fossem organizados e uniformizados para uso em todo o território nacional. Uma retomada dos estudos ocorreu a partir de 1990, quando um número expressivo de trabalhos foi apresentado no Congresso Brasileiro de Ciência do Solo e, apenas nos últimos cinco anos, organizados dois encontros regionais para discussão do assunto. A falta de definição de parâmetros que indiquem a presença do atributo coeso e, ainda, de diferentes graus de coesão, impossibilita que se realize um reconhecimento fácil e seguro do mesmo.

Os estudos sobre o atributo hardsetting vem de longa data, e uma série de avanços auxiliaram num melhor entendimento e no estabelecimento de parâmetros mais confiáveis para a identificação dos solos hardsetting. Alguns parâmetros quantitativos, que já vêm sendo utilizados na identificação dos solos hardsetting, como por exemplo, o comportamento das curvas de resistência do solo ou o índice de resistência máxima, podem ser testados nos solos com horizontes coesos brasileiros, associados aos constantes valores elevados de densidade do solo. Esses parâmetros podem ser utilizados no estabelecimento de novos grupamentos de solos no sistema taxonômico brasileiro, em níveis hierárquicos inferiores. O conteúdo de água na resistência máxima também 
pode ser um parâmetro auxiliar para a subdivisão de classes de solos que manifestem o caráter coeso.

O uso de atributos morfológicos para o reconhecimento do caráter coeso, como é o caso particular da estrutura maciça moderadamente coesa a coesa, é de valor limitado como feição distintiva auxiliar, já que o caráter "coeso" não se manifesta quando o solo está úmido.

Como no caso do hardsetting, o comportamento coeso não deveria estar vinculado apenas a um Grupo geológico específico (Barreiras, no caso), mas a solos que reunam as características gerais que se enquadrem dentro daquele comportamento. Desta maneira, é importante que a definição do caráter permita a inclusão de solos formados a partir de outros materiais.

A vasta literatura sobre solos hardsetting pode servir como fonte imprescindível de consulta para pesquisas desenvolvidas com solos coesos no Brasil, pois os parâmetros do horizonte coeso analisados foram similares àqueles utilizados para definir 0 comportamento hardsetting nos solos australianos, sugerindo tratar-se da mesma propriedades de solo. 


\section{REFERÊNCIAS BIBLIOGRÁFICAS}

ALMEIDA, J.A.; KÄMPF, N.; KLAMT, E. Amidas e hidrazina na identificação de caulinita desordenada em solos brunos subtropicais do Rio Grande do Sul e de Santa Catarina. Revista Brasileira de Ciência do Solo, v.16, p.169-175, 1992.

ANJOS, L.H.C. Caracterização, gênese, classificação e aptidão agrícola de uma seqüência de solos do Terciário na região de Campos, RJ. Itaguaí, 1985. 194p. Dissertação (Mestrado) - Universidade Federal Rural do Rio de Janeiro.

ARAUJO FILHO, J.C.; CARVALHO, A.; SILVA, F.B.R. e. Investigações preliminares sobre a pedogênese de horizontes coesos em solos dos tabuleiros costeiros do Nordeste do Brasil. In: WORKSHOP COESÃO EM SOLOS DOS TABULEIROS COSTEIROS, Aracaju, 2001. Anais. Aracaju: Embrapa Tabuleiros Costeiros, 2001. p.123-142.

BECHER, H.H.; BREUER, J.; KLINGER, B. An index value for characterizing hardsetting soils by fall-cone penetration. Soil Technology, v.10, p.47-56, 1997.

BLAKE, G.R.; HARTGE, K.H. Bulk density. In: KLUTE, A. (Ed.). Methods of soil analysis - physical and mineralogical methods. 2.ed. Madison: American Society of Agronomy, 1986. v.1, p. 363-375.

BREUER, J.; SCHWERTMANN, U. Changes to hardsetting properties of soil by addition of metal hydroxides. European Journal of Soil Science, v.50, p.657-664, 1999.

BREWER, R. Fabric and mineral analysis of soils. New York: Robert Krieger, 1976. 482p.

BREWER, R.; SLEEMAN, J.L. Soil structure and fabric. Adelaide: CSCIRO, 1988. $173 p$. 
BUSSCHER, W.J. Corretion of cone index for soil water content differences in a coastal plain soil. Soil \& Tillage Research, v.43, p.205-217, 1997.

BUTLER, B.E. Soil classification for soil survey. Oxford: Clarendon Press, 1980.

CARVALHO, C.C.N. de. Gênese e transformação de solos em um tabuleiro do recôncavo baiano. Salvador, 2001. 116p. Dissertação (Mestrado) - Universidade Federal da Bahia.

CAUSARANO, H. Factors affecting the tensile strength of soil aggregates. Soil \& Tillage Research, v.28, p.15-25, 1993.

CHARTRES, C.J.; NORTON, L.D. Micromorphological and chemical properties of Australian soils with hardsetting and duric horizons. In: RINGROSE-VOASE, A.J.; HUMPHREYS, G.S. (Ed.) Soil micromorphology. Amsterdam: Elsevier, 1994. p.825-834. (Developments in Soil Science, 22).

CHARTRES, C.J.; FITZGERALD, J.D. Properties of siliceous cements in some australian soils and saprolites. Developments in Soil Science, v.19, p.199-205, 1990.

CHARTRES, C.J.; KIRBY, J.M.; RAUPACH, M. Poorly Ordered Silica and Aluminosilicates as Temporary Cementing Agents in Hard-Setting Soils. Soil Science Society of America Journal, v.54, p.1060-1067, 1990.

COMISSÃO EXECUTIVA DO PLANO DA LAVOURA CACAUEIRA. Guia da excursão técnica: solos coesos de Tabuleiros Costeiros - Ilhéus, Centro de Pesquisas do Cacau. Campinas: Fundação Cargill, 1998. 84p.

DEXTER, A. R.; KROESBERGEN, B. Methodology for determination of tensile strength of soil aggregates. Journal of Agricultural Engineering Research v.31, p.139-147, 1985.

DEXTER, A. R.; WATTS, C.W. Tensile strengh and friability. In: SMITH, K.A.; MULLINS, C.E. (Ed.). Soil and environmental analysis: physical methods. 2.ed. New York: Marcel Dekker, 2000. p.401-430.

DEXTER, A.R.; HORN, R.; KEMPER, W.D. Two mechanisms for age-hardening of soil. Journal of Soil Science, v.30, p.163-175, 1988. 
EMPRESA BRASILEIRA DE PESQUISA AGROPECUÁRIA. Centro Nacional de Pesquisa de Mandioca e Fruticultura. Relatório técnico anual - 1980. Cruz das Almas, 1981. 209p.

EMPRESA BRASILEIRA DE PESQUISA AGROPECUÁRIA. Serviço Nacional de Levantamento e Conservação de Solos. Manual de métodos de análise de solo. Rio de Janeiro: Ministério da Agricultura, 1979b. 1v.

EMPRESA BRASILEIRA DE PESQUISA AGROPECUÁRIA. Centro Nacional de Pesquisa de Solos. Sistema brasileiro de classificação de solos. Rio de Janeiro: Embrapa Solos, 1999. 412p.

EMPRESA BRASILEIRA DE PESQUISA AGROPECUÁRIA. Centro Nacional de

Pesquisa de Solos. Reunião de classificação, correlação e aplicação de levantamento de solos, 4., Rio de Janeiro, 1994. Anais. Rio de Janeiro: EMBRAPA, CNPS, 1995. 157p.

EMPRESA BRASILEIRA DE PESQUISA AGROPECUÁRIA. Serviço Nacional de Levantamento de Solos. Reunião técnica de levantamento de solos, 10, Rio de Janeiro, 1979. Súmula. Rio de Janeiro: EMBRAPA, SNLCS, 1979a. 83p.

ESTADOS UNIDOS. Department of Agriculture. Natural Resources Conservation Service. Soil Survey Staff. Keys to soil taxonomy. 8.ed. Washington, 1998. $326 \mathrm{p}$.

FONSECA, O.O.M. Caracterização e classificação de solos latossólicos e podzólicos desenvolvidos nos sedimentos do Terciário no litoral brasileiro. Itaguaí, 1986. 185p. Dissertação (Mestrado) - Universidade Federal Rural do Rio de Janeiro.

FRANZMEIER, D.P.; CHARTRES, C.J.; WOOD, J.T. Hardsetting soils in Southeast Australia: landscape and profile processes. Soil Science Society of America Journal, v.60, p.1178-1187, 1996.

GIAROLA, N.F.B.; SILVA, A.P. da; TORMENA, C.; SOUZA, L.S.; RIBEIRO, L. da P. Similaridades entre o caráter coeso dos solos e o comportamento hardsetting: estudo de caso. Revista Brasileira de Ciência do Solo, v.25, p.239-247, 2001. 
GUSLI, S.; CASS, A .; MACLEOD, D.A.; BLACKWELL, P.S. Structural collapse and strength of some Australian soils in relation to hardsetting: II. Tensile strength of collapsed aggregates. European Journal of Soil Science, v.45, p.23-29, 1994.

HALL, D.J.M.; McKENZIE, D.C.; MacLEOD, D.A.; BARRET, A. Amelioration of a hardsetting alfisol through deep mouldboard ploghing, gypsum application and double cropping. I. Soil physical and chemical properties. Soil \& Tillage Research, v.28, p.253-270, 1994.

HARLAN, P.W.; FRANZMEIER, D.P.; ROTH, C.B. Soil formation on loess in southwester Indiana. II. Distribution of clay and free oxides and fragipan formation. Soil Science Society of America Journal, v.41, p.99-103, 1977.

HARPER, R.J.; GILKES, R.J. Hardsetting in the surface horizons of sandy soils and its implications for soil classification and management. Australian Journal of Soil Research, v.32, p.603-619, 1994.

IMHOFF, S.; SILVA, A.P. da; DEXTER, A.R. Factors contributing to the tensile strength and friability of Oxisols. Soil Science Society of America Journal, v.69, 2002. / No prelo /.

IMHOFF, S.; SILVA, A.P. da; TORMENA, C.A. Spatial heterogeneity of soil properties in areas under elephant-grass short-duration grazing system. Plant and Soil, v.219, p.161-168, 2000.

ISBELL, R.F. The Australian soil classification. Melbourne: CSIRO, 1996. 160p.

JACOMINE, P.K.T. Distribuição geográfica, características e classificação dos solos coesos dos Tabuleiros Costeiros. In: REUNIÃO TÉCNICA SOBRE SOLOS COESOS DOS TABUlEIROS, Cruz das Almas, 1996. Pesquisa e desenvolvimento para os Tabuleiros Costeiros: anais. Aracaju: EMBRAPA, CPATC; EMBRAPA, CNPMF; EAUFBA; IGUFBA, 1996. p.13-26.

JACOMINE, P.K.T. Evolução do conhecimento sobre solos coesos no Brasil. In: WORKSHOP COESÃO EM SOLOS DOS TABULEIROS COSTEIROS, Aracaju, 2001. Anais. Aracaju: Embrapa Tabuleiros Costeiros, 2001. p.19-46.

JACOMINE, P.K.T.; MONTENEGRO, J.O.; RIBEIRO, M.R. Levantamento exploratório-reconhecimento de solos do Estado de Sergipe. Recife: 
EMBRAPA; CPP; SUDENE; DRN; MA; CONTAP; USAID; ETA, 1975. 506p. (Boletim Técnico, 36; Série Recursos de Solos, 6).

KLUTE, A. Water retention: laboratory methods. In: KLUTE, A. (Ed.) Methods of soil analysis. Part 1, Physical and mineralogical methods. 2.ed. Madison: SSSA, 1986. v.1, p.635-662.

LAMOTTE, M.; BRUAND, A.; HUMBEL, F.X.; HERBILLON, A.J.; RIEU, M. A hard sandy-loam soil from semi-arid Northern Cameroon: I. Fabric of the groundmass. European Journal of Soil Science, v.48, p.213-225, June, 1997a.

LAMOTTE, M.; BRUAND, A.; OHNENSTETTER, D.; IDELFONSE, P.; PÉDRO, G.

A hard sandy-loam soil from semi-arid Northern Cameroon: II. Geochemistry and mineralogy of bonding agent. European Journal of Soil Science, v.48, p.227-237, June, $1997 b$.

LARSON, W.E.; GUPTA, S.C. Estimating critical stresses in unsaturated soils from changes in pore water pressure during confined compression. Soil Science Society of American Journal, v.44, p.1127-1132, 1980.

LEMOS, R.C.; SANTOS, R.D. Manual de descrição e coleta de solos no campo. 3.ed. Campinas: Sociedade Brasileira de Ciência do Solo, 1996. 45p.

LEY, G.J.; LARYEA, K.B. Spatial variability in penetration resistance of a hardsetting tropical alfisol. Soil \& Tillage Research, v.29, p.367-381, 1994.

LEY, G.J.; MULLINS, C.A.; LAL, R. Hard-setting behaviour of some structurally weak tropical soils. Soil \& Tillage Research, v.13, p.365-381, 1989.

LEY, G.J.; MULLINS, C.A.; LAL, R. Effects of soil properties on the strength of weakly structured tropical soils. Soil \& Tillage Research, v.28, p.1-13, 1993.

LEY, G.J.; MULLINS, C.A.; LAL, R. The potential restriction to root growth in structurally weak Tropical soils. Soil \& Tillage Research, v.33, p.133-142, 1995.

LIMA, P. C. de; CURI, N.; LEPSCH, I. F. Terminologia de micromorfologia do solo. Boletim Informativo da Sociedade Brasileira de Ciência do Solo, v.10, n.2, p.3343, 1985.

MASLE, A.; PASSIOURA, J.B. Effect of soil strength on the growth of young wheat plants. Australian Journal of Plant Physiology, v.14, p.634-656, 1987. 
McDONALD, R.C.; ISBELL, R.F.; SPEIGHT, J.G.; WALKER, J.; HOPKINS, M.S. Australian soil and land survey: field handbook. 2.ed. Melbourne: CSIRO, 1998. $190 \mathrm{p}$.

McDONALD, R.C.; ISBELL, R.F.; SPEIGHT, J.G.; WALKER, J.; HOPKINS, M.S. Australian soil and land survey: field handbook. Melbourne: Inkata Press, 1984. 190p.

McKYES., E.; NYAMUGAFATA, P.; NYAMAPFENE, K.W. Characterization of cohesion, friction and sensitivity of two hardsetting soils from Zimbabwe. Soil \& Tillage Research, v.29, p.357-366, 1994.

MUGGLER, C.C., VAN GRIETHUYSEN, C., BUURMAN, P.; PAPE, T. Aggregation, organic matter, and iron oxide morphology in Oxisols from Minas Gerais, Brazil. Soil Science, v.164, p.759-770, 1999.

MULLINS, C.E. Hardsetting soils. In: SUMNER, M.E. (Ed.). Handbook of soil science. New York: CRC Press, 1999. p.G65-G87.

MULLINS, C.E. Hardsetting. In: LAL, R.; BLUM, W.H.; VALENTINE, C.; STEWART, B.A. (Ed.) Methods for assesment of soil degradation. New York: CRC Press, 1997. p.109-128. (Advances in Soil Science, 19).

MULLINS, C.E. Hardsetting. In: LAL, R.; BLUM, W.H.; VALENTINE, C.; STEWART, B.A. (Ed). Methods for assessment of soil degradation. New York, CRC Press, 1989. p.109-128. (Advances in Soil Science, ).

MULLINS, C.E.; BLACKWELL, P.S.; TISDALL, J.M. Strength development during drying of a cultivated, flood-irrigated hardesetting soil. I. Comparison with a structurally stable soil. Soil \& Tillage Research, v.25, p.113-128, 1992a.

MULlinS, C.E.; CASS, A.; MacLEOD, D.A.; HALL, D.J.M.; BLACKWELL, P.S. Strength development during drying of a cultivated, flood-irrigated hardesetting soil. II. Trangie soil, and comparison with theorical predictions. Soil \& Tillage Research, v.25, p.129-147, $1992 b$.

MULLINS, C.E.; MacLEOD, D.A.; NORTHCOTE, K.H.; TISDALL, J.M.; YOUNG, I.M. Hardsetting soils: behaviour, ocurrence and management. In: LAL, R.; 
STEWART, B.A. (Ed.) Soil Degradation. New York, Springer-Verlag, 1990. p.37-108 (Advances in Soil Science, 11).

MULLINS, C.E.; PANAYIOTOPOULOS, K.P. The strengh of unsatured mixture of sand and caolin and the concept of effective stress. Journal of Soil Science, v.35, p.459-468, 1984.

MULLINS, C.E.; YOUNG, I.M.; BENGHOUGH, A.G.; LEY, G.J. Hard-setting soils Soil Use and Management, v.3, p.79-83, 1987.

NACIF, P.G.S. Efeitos da subsolagem em propriedades físico-hídricas de um Latossolo Amarelo Álico coeso, representativo do Recôncavo Baiano. Viçosa, 1994, 75p. Dissertação (Mestrado) - Universidade Federal de Viçosa.

NASCIMENTO, G.B. do. Caracterização dos solos e avaliação de propriedades edáficas em ambiente de Tabuleiros Costeiros da região Norte Fluminense (RJ). Rio de Janeiro, 2001, 162p. Dissertação (Mestrado) - Universidade Federal Rural do Rio de Janeiro.

NIELSEN, D.R.; BIGGAR, J.W.; ERH, K.T. Spacial variability of soil water properties. Hilgardia, v.42, p.215-259, 1973.

NOGUEIRA, L.R.Q. Demandas e propostas de pesquisa para os solos coesos dos Tabuleiros Costeiros. In: REUNIÃO TÉCNICA SOBRE SOLOS COESOS DOS TABUlEIROS COSTEIROS, Cruz das Almas, 1996. Pesquisa e desenvolvimento para os Tabuleiros Costeiros; anais. Aracaju: EMBRAPA, CPATC; EMBRAPA, CNPMF; EAUFBA; IGUFBA, 1996. p.76-80.

NORRISH, K.; PICKERING, J.G. Clay minerals. In: Soils: an australian viewpoint. Melbourne: CSIRO, 1983. p.281-308.

NORTHCOTE, K.H. A factual key for the recognition of Australian soils. Division of Soils. Melbourne: CSIRO, 1960. 120p. (Divisional Report, 4/60).

NORTHCOTE, K.H. A factual key for the recognition of Australian soils. 3.ed. Glenside: Rellium Technical, 1971. 123p.

NORTHCOTE, K.H. A factual key for the recognition of Australian soils. 4.ed. Glenside: Rellium Technical, 1979. 123p. 
NORTHCOTE, K.H.; HUBBLE, G.D.; ISBELL, R.F.; THOMPSON, C.F.; BETTANY, E. A description of Australian soils. Melbourne: CSIRO, 1975. 170p.

OLIVEIRA, L.B. de; DANTAS, H.S.; CAMPELO, A.B.; GALVÃO, S.J.; GOMES, I.F. Caracterização de adensamento no subsolo de uma área de "tabuleiro" da Estação Experimental do Curado, Recife. Pesquisa Agropecuária Brasileira, v.3, p.207214, 1968.

OLIVEIRA, L.B. de; MELO, V. de. Caracterização físico-hídrica do solo. I. Unidade Itapirema. Pesquisa Agropecuária Brasileira, v.5, p.35-48, 1970.

PEFECT, E.; KAY, B.D.; SILVA, A. P. da. Influence of soil properties on statistical characterization of dry aggregate strength. Soil Science Society of America Journal, v.59, p.532-537, 1995.

POCH, R.M.; VERPLANCKE, H. Penetration resistance of gypsiferous horizons. European Journal of Soil Science, v.48, p.535-543, Sept. 1997.

PONTE, C.M.; RIBEIRO, L.P. Estudo da gênese de horizontes coesos em uma toposseqüência na área do Candeal - Escola de Agronomia da UFBA. Salvador: IGEO;UFBA, 1990.

RAHIMI, H.; PAZIRA, E.; TAJIK, F. Effect of soil organic matter, electrical conductivity and sodium adsorption ratio on tensile strength of aggregates. Soil $\boldsymbol{\&}$ Tillage Research, v.54, p.145-153, 2000.

REZENDE, J.O. Solos coesos dos tabuleiros costeiros: limitações agrícolas e manejo. Salvador: SEAGRI, SPA, 2000. 117p. (Série Estudos Agrícolas, 1).

RIBEIRO, L.P. Sílica em horizontes coesos de solos da Bahia. Universitas, n.38, p.5980, 1986.

RIBEIRO, L.P. Primeiras avaliações sobre a gênese dos solos coesos da região de Cruz das Almas - BA. Salvador: Curso de Pós-Graduação em Geociências da UFBA, 1991. 33p.

RIBEIRO, L.P. Os latossolos amarelos do recôncavo baiano: gênese, evolução e degradação. Salvador: Seplantec; CADCT, 1998. 99p.

RIBEIRO, L.P. Evolução da cobertura pedológica dos tabuleiros costeiros e a gênese dos horizontes coesos. In: WORKSHOP COESÃO EM SOLOS DOS 
TABULEIROS COSTEIROS, Aracaju, 2001. Anais. Aracaju: Embrapa Tabuleiros Costeiros, 2001. p.93-121.

RIBEIRO, M.R. Características morfológicas dos horizontes coesos dos solos dos Tabuleiros Costeiros. In: WORKSHOP COESÃO EM SOLOS DOS TABULEIROS COSTEIROS, Aracaju, 2001. Anais. Aracaju: Embrapa Tabuleiros Costeiros, 2001. p.161-168.

SANTOS, D.M.B. Efeitos da subsolagem mecânica sobre a estrutura de um solo de “tabuleiro" (Latossolo Amarelo Álico coeso) no município de Cruz das Almas Bahia (Caso 2). Salvador, 1992. 87p. Dissertação (Mestrado) - Universidade Federal da Bahia.

SILVA, A.J.N.; RIBEIRO, M.R.; MERMUT, A.R.; BENKE, M.B. Influência do cultivo contínuo da cana-de-açúcar em Latossolos Amarelos coesos do Estado de Alagoas: propriedades micromorfológicas. Revista Brasileira de Ciência do Solo, v.22, p.515-525, 1998.

SILVA, A.P. da.; KAY, B.D.; PERFECT, E. Management versus inherent soil properties effects on bulk density and relative compaction. Soil \& Tillage Research, v.44, p.81-93, 1997.

SILVA, M.S.L. Efeito do cultivo da cana-de-açúcar em propriedades do solo de tabuleiro do estado de Alagoas. Recife, 1989. 106p. Dissertação (Mestrado) Universidade Federal de Pernambuco.

SILVA, M.S.L. Caracterização de Latossolos Amarelos sob cultivo contínuo de canade-açúcar no Estado de Alagoas. Recife, 1996. 133p. Tese (Doutorado) Universidade Federal de Pernambuco.

SILVA, M.S.L.; RIBEIRO, M.R. Influência do cultivo contínuo da cana-de-açúcar em propriedades morfológicas e físicas de solos argilosos de tabuleiro no estado de Alagoas. Revista Brasileira de Ciência do Solo, v.16, p.397-402, 1992.

SKIDMORE, E.L.; LAYTON, J.B. Dry-soil aggregate as influenced by selected soil properties. Soil Science Society of America Journal, v.56, p.557-561, 1992.

SMECK, N.E.; CIOLKOSZ, E.J. (Ed.). Fragipans : their occurrence, classification and genesis. Madison: SSSA, 1989, 153p. (Special Publication, 24). 
SMITH, C.W.; JOHNSTON, M.A.; LORENTZ, S. The effect of soil compaction and soil physical properties on the mechanical resistance of South African forestry soils. Geoderma, v.78, p. 93-111, 1997.

STATISTICAL ANALYSIS SYSTEM INSTITUTE. SAS/STAT Procedure guide for personal computers. Version 5, SAS Inst. Cary, NC., 1991.

TENNANT, D.; SCHOLZ, G.; DIXON, J.; PURDIE, B. Physical and chemical characteristics of duplex soils and their distribution in the south-west of Western Australia. Australian Journal of Experimental Agriculture, v.32, p.827-843, 1992.

TISDALL, J.M.; ADEM, H.H. Effect of water content of soil at tillage on sizedistribution of aggregates and infiltration. Australian Journal of Experimental Agriculture, v.26, p.193-195, 1986.

TOWNER, G.D.; CHILDS, E.C. The mechanical strength of unsaturated porous granular material. Journal of Soil Science, v.23, p.481-498, 1972.

UCHA, J.M. Processos de transformação Latossolo-Espodossolo sobre os sedimentos do Grupo Barreiras nos tabuleiros costeiros do Litoral Norte do Estado da Bahia. Salvador, 2000. 196p. Tese (Doutorado) - Universidade Federal da Bahia.

VEPRASKAS, M.J. Cone index of loamy sands as influenced by pore size distribution and effective stress. Soil Science Society of America Journal, v.48, p.1220-1225, 1984.

VETTORI, L. Métodos de análises de solos. Rio de Janeiro: Ministério da Agricultura, 1969. 24p. (Boletim Técnico, 7).

WATTS, C.; A.R. DEXTER. Soil friability: theory, measurement and the effects of management and organic carbon content. European Journal of Soil Science, v.49, p.73-84, 1998.

WATTS, C.; A.R. DEXTER. The influence of organic matter in reducing the destabilization of soil by simulated tillage. Soil \& Tillage Research, v.42, p.253$275,1997$. 
WEAICH, K.; BRISTOW, K.L.; CASS, A. Pre-emergent shoot growth of maize under different drying conditions. Soil Science Society of America Journal, v.56, p.1272-1278, 1992a.

WEAICH, K.; CASS, A.; BRISTOW, K.L. Use of a penetration resistance characteristic to predict soil strength development during drying. Soil \& Tillage Research, v.25, p.149-166, 1992.

WEAICH, K.; CASS, A.; BRISTOW, K.L. Use of a penetration resistance characteristic to predict soil strength development during drying. Soil \& Tillage Research, v.25, p.149-166, 1992b.

WILLIAMS, J.; SHAYKEWICH, C.F. The influence of soil water matric potential on the strength properties of unsaturated soil. Soil Science Society of America Proceedings, v.34, n.6, nov/dec, p.835-840, 1970.

YOUNG, I.M. Hardsetting soils in the UK. Soil \& Tillage Research, v.25, p.187-193, 1992.

YOUNG, I.M.; MULlinS, C.E.; COSTIGAN, P.A.; BENGOUGH, A.G. Hardsetting and structural regeneration in two unstable Britsh sandy loams and their influence on crop growth. Soil \& Tillage Research, v.19, p.383-394, 1991. 